DIW BERLIN

Discussion

Papers

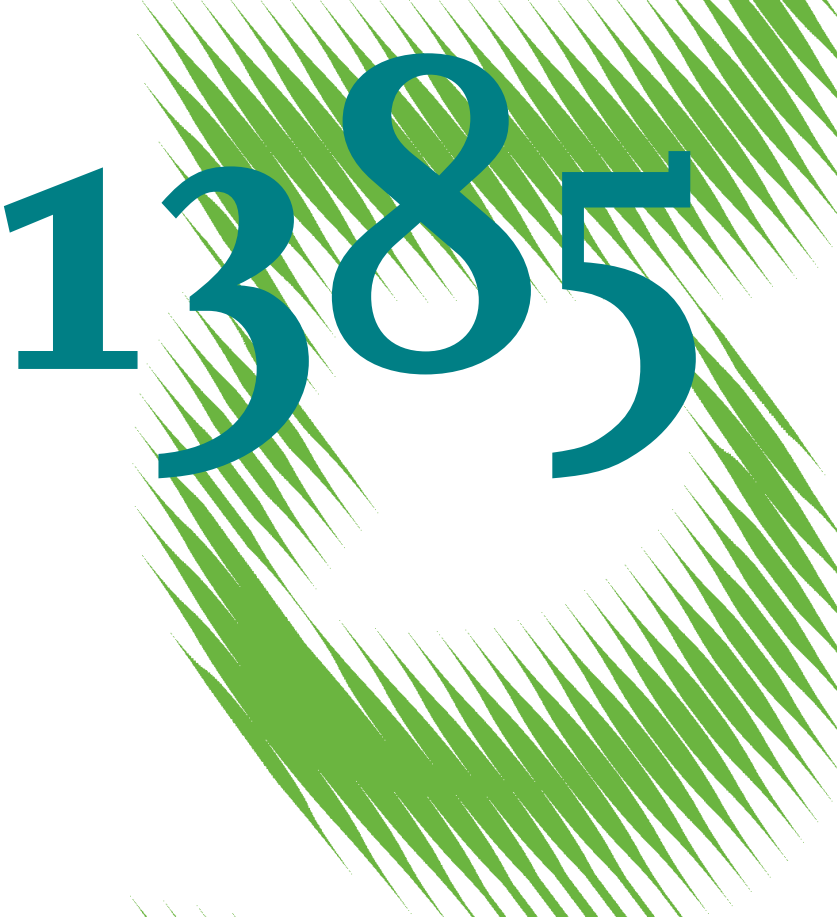

Capacity Mechanisms on Central European Electricity Markets

Effects on Consumers, Producers and Technologies until 2033 
Opinions expressed in this paper are those of the author(s) and do not necessarily reflect views of the institute.

IMPRESSUM

(C) DIW Berlin, 2014

DIW Berlin

German Institute for Economic Research

Mohrenstr. 58

10117 Berlin

Tel. $+49(30) 89789-0$

Fax +49 (30) $89789-200$

http://www.diw.de

ISSN print edition $1433-0210$

ISSN electronic edition 1619-4535

Papers can be downloaded free of charge from the DIW Berlin website:

http://www.diw.de/discussionpapers

Discussion Papers of DIW Berlin are indexed in RePEc and SSRN:

http://ideas.repec.org/s/diw/diwwpp.html

http://www.ssrn.com/link/DIW-Berlin-German-Inst-Econ-Res.html 


\title{
Capacity Mechanisms on Central European Electricity Markets: Effects on Consumers, Producers and Technologies until $2033^{1}$
}

\author{
Thure Traber ${ }^{2}$
}

\begin{abstract}
The reduced attractiveness of investments in reliable power plants under conditions of liberalized markets and the transition towards renewable energies has brought a discussion on capacity policies to Europe. We use a partial equilibrium model to compare important effects of three basic policies. A strategic reserve policy and a capacity market policy with administratively set capacity targets, and the obligation of generators to hold certificates of reliable capacities in relation to their supply. We find important differences of policies for consumers and producers that are depending on existing power plant structure and the elasticity of demand particularly in the medium term perspective until the year 2023. In the longer term until 2033 the results differ less pronounced. However, for the German case we demonstrate the potential to effectively reduce the burden on the economy to achieve a prescribed target through the implementation of a capacity certificate system.
\end{abstract}

JEL classification: C63; D47; D61 Keywords: electricity market; capacity mechanism; investment model

\section{Introduction}

After fifteen years of market liberalization, the establishment of central market places with considerable volume, and with the development of renewables in central Europe, energy policy has recently turned its attention to the issue of reliability of power supply. In Germany, a perception of an endangered reliability in situations of peak demand in the near future stems basically from four elements which shape the prospects for future investments: low energy demand growth, pronounced renewable energy roll-out, low emission prices, and excessive conventional power plant investment in previous years.

Low energy demand growth is partly due to the combination of the dip in economic growth caused by the financial crisis, and a reduction of energy intensity of

\footnotetext{
${ }^{1}$ Financial support by the Mercator foundation is gratefully acknowledged.

${ }^{2}$ German Institute for Economic Research (DIW Berlin) , Mohrenstr. 58, D-10117 Berlin, Germany; Email: ttraber@diw.de, Tel.: +49-30-89789409, Fax: +49-30-89789113.
} 
GDP in central Europe ${ }^{3}$. This development is accompanied, by a strong roll-out of renewable energy and continued erection of coal power plants. In the last five years Germany experienced a roll-out of photovoltaics of more than $30 \mathrm{GW}$, while within the years 2011 to 2014 alone about 10 GW of new coal fired power plants will have been commissioned. As a result, electricity spot market and future prices on the central European power market places have shown successive reductions after a last peak directly after the German nuclear power moratorium ${ }^{4}$. Low energy demand and a generous allocation of bankable emission allowances, together with expectations of only small reductions of the emission cap has furthermore resulted in very low emission prices and low emission price prospects. With the decrease of price spreads due to a peak shaving effect of PV, prospects for mid- and peak load plants, i.e. combined cycle gas turbines (CC) and gas turbines (GT) as well as storage plants, have deteriorated. In addition, high European gas prices compared to coal prices put gas fired power plant investments in an unfavorable situation. By contrast, both low emission prices and coal prices favor coal fired power plants. However, high emission of polluting gases, public opinion against new coal fired power plant construction, and decreasing full load hours are diminishing the prospects for new capital-intensive coal fired power plants as well.

Against this background, further $12 \mathrm{GW}$ of nuclear capacity is scheduled to be phased out by 2022, such that the supply situation in southern Germany might become strained: load centers and most nuclear plants scheduled to be decommissioned are located in the south, while the bulk of new coal fired power plants is constructed in the north. Similar conditions are expected for the French power market, where the implementation of a high level government announcement ${ }^{5}$ would effectively reduce the planned operating lifetime of nuclear power plants by about five years. While replacement is unlikely due to pronounced increases in cost for new nuclear power plants, this results in a reduction of installed net nuclear generation capacity in France of more than 35 GW in the decade from 2023 to 2033.

Low energy prices and resulting low energy investment prospects should not alarm policy makers, if demand response to price peaks were sufficient. Moreover, high electricity prices are under supervision of competition authorities, and are influenced by further policy measures which obscure the revelation of costs through these markets. In addition, it is argued that power plant projects are time consuming so that scarcity prices that correctly signal the demand for capacity may prevail until the new capacities are built and potentially create large transfers from consumers to producers (Oren (2003), de Vries and Hakvoort (2004)). These arguments lead to the suspicion of possible market failure regarding incentives to build adequate capacity, and a related call for capacity support instruments especially in times of

\footnotetext{
${ }^{3}$ See for instance the energy intensity of the economy documented at Eurostat http://epp.eurostat.ec.europa.eu. France, Germany and Poland experienced reductions in energy consumption per GDP of between 13 and 25 percent in the decade prior to 2011 .

${ }^{4}$ Prices at the European Energy Exchange are documented at the website EEX.com. For instance Phelix futures contracts for delivery of baseload energy in 2016 fell from 65 Euro per MWh to below 40 Euro per MWh between July 2010 and July 2013.

${ }^{5}$ Declaration of the President of France at the environmental conference in Paris on the 12th of September 2012.
} 
comparatively low energy prices as currently experienced in central Europe.

Dating back to the era of electricity supply by regulated monopolies, the economic literature has been concerned with how to price and incentivize efficient capacity levels. The peak load pricing literature in the field of electricity started with the analysis of cases in a deterministic setting. Boiteux (1960) finds that while off peak consumers should pay only the marginal costs, marginal costs as well as capacity costs have to be born by peak load consumers. These insights were further elaborated by Crew and Kleindorfer who introduce a multiplicity of technologies and demand uncertainty. Their numerical results illustrate that as the diversity of technology increases, a higher level of security of supply becomes desirable. They state the "analysis indicates that a practical evaluation of optimal safety margins is [...] involving a simultaneous assessment of pricing and capacity [...]" (Crew and Kleindorfer (1976)). Chao (1983) extended these findings by also including uncertainty on the supply side. He finds that plant outage probabilities, the cost differentials between technologies and the time length of peak load events have to be considered under uncertainty to derive optimal time differentiated pricing. In summary, the basic insight provided by this literature is that efficient prices include a mixture of marginal costs and fixed costs, where fixed costs are covered mainly in periods with more than average consumption and corresponding high probabilities for a loss of load. Moreover, the optimal mixture of price components itself depends on the time profiles of the involved uncertainties regarding demand conditions and the availability of technologies.

Most of these peculiarities are reflected in Joskow and Tirole (2007) who additionally introduce rationing in their analytical model and develop simple rules for second best solutions given some consumers cannot respond to prices. They show how price caps reduce the reliability of the system and how reliability standards can be introduced to compensate for these deficiencies and the missing money problem induced by price caps in particular. Joskow, however, stresses the view that price caps are unlikely to be the sole source of the so-called missing money problem and proposes a set of measures that can be used to remedy some apparent problems of wholesale markets: (a) raising the price caps, (b) require prices to rise to the price caps if the system operator has to take out of market actions (e.g. redispatch), (c) increase real-time demand response, $(\mathrm{d})$ include more operating reserves products in the market, and (e) review and adjust reliability rules and protocols (Joskow (2006), Joskow (2008)). Similarly, de Vries and Hakvoort (2004) summarize a variety of reasons in addition to price restriction, which may cause the market to fail to induce efficient investment levels. In particular, they point to the potential problem of imperfect information of investors in regard to stochastic demand and supply developments, as also described by Hobbs et al. (2002). A potentially more severe problem may be caused by regulatory uncertainty for instance with respect to emission policy, nuclear energy policy, renewable energy policy, and the enforcement of competition policy with corresponding adjustments of price caps. These uncertainties have especially pronounced consequences when investors choose a risk averse strategy, which may be profitable as has been pointed at by Vásquez et al. (2002). 
Several of the aforementioned papers also quantify effects of the introduction of possible policies that are designed to remedy the potential market failures including their negative effects on reliability. For this aim, these studies predominantly use stochastic programming techniques under the assumption of inelastic demand (de Vries and Heijnen (2008), Hobbs et al. (2002), Vásquez et al. (2002)). Overall, the results of these modeling exercises are inconclusive, and it is stressed that the relative advantages of certain policies over competing measures are depending on the system characteristics under consideration. An important question related to the policy effectiveness and efficiency concerns the distributional effects of the instruments, which have not been studied earlier and are addressed in this paper. We model three instruments under discussion in the European debate and assume elastic market demand. This enables an assessment of the effects of different policies on consumers, producers and technologies.

Three basic instruments for the support of reliability are investigated in this paper, which can be classified as firm capacity based and reserve capacity based mechanisms. Firm capacity is rewarded under a capacity market. As the simplest form of capacity mechanism, a capacity market arises from an administratively set binding capacity target and rewards all firm capacity needed to reach the target with a corresponding payment. Instead of targeting firm capacity, we also consider mechanisms that more directly incentivize reserve capacity. This is implemented by an obligation of suppliers or by a strategic reserve policy. Under both regulations, a part of the power plant park is used only under predefined extreme conditions. In case of a strategic reserve, a regulator acquires as much capacities not sustained by the energy market as the fulfillment of her target requires. By contrast, the supply obligation leaves the exact amount of reserves to the market, but prescribes a capacity margin, which obliges suppliers to hold reserve capacities in excess of their expected energy supply peak. This regulation establishes a market for reserve capacities, if cost structures vary across firms as in the examples analyzed in this paper.

\section{Model overview}

In the following, models for the simulation of a capacity market, a strategic reserve policy, and an capacity obligation with capacity certificates are introduced. They are all based on the model of an energy only market which is described in the next subsection.

\subsection{Basic energy only market model}

We first model a basic energy only market with power generation and plant investment of firms acting on a domestic market. The time horizon consists of single periods $y$, each consisting of a number of time steps $t$. Variable unit costs are constant in output $q$ in each period and include payments for emission allowances. They 
write:

$$
C_{q}^{y, n}=\frac{p^{y, n}+\phi^{y} e^{n}}{\eta^{n}}+o c^{n},
$$

where $\phi^{y}$ denotes the periodic emissions price, and $p^{y, n}, e^{n}, \eta^{n}$ and $o c^{n}$ denote the periodic fuel price, the specific fuel emission, the degree of efficiency, and the unit operation and maintenance costs of technology $n$ respectively. Fixed cost accrue proportional to investments $k$ and are denoted $F^{n}$.

Firms are assumed to behave competitively and to have perfect foresight. In particular, firms perfectly assign frequencies $f(\omega)$ to residual demand events denoted $\omega$. Inverse demand is denoted $P^{y, t, \omega}\left(X^{y, t, \omega}\right)$, where $X$ denotes total consumption.

Now the profit maximization problem with regard to production $q$, and investment $k$ of a representative firm $i$ can be written as

$\max _{q, k} \pi^{i}=\sum_{y=1}^{Y}\left(\frac{1}{1+\delta}\right)^{y} \sum_{n=1}^{N} \sum_{t=1}^{T} \sum_{\omega=1}^{\Omega}\left(f(\omega)\left(P^{y, t, \omega}\left(X^{y, t, \omega}\right)-C_{q}^{y, n}\right) q^{i, y, n, t, \omega}-F^{n} k^{i, y, n}\right)$.

The formulation in (2) simply says that profits are the sum of frequency weighted, discounted differences between revenues and variable costs minus the discounted sum of investment costs.

The choice of the decision variables is bound by the following two restrictions. The first restriction ensures that production does not exceed the maximum of available installed net generation capacity $\bar{q}^{i, y, n}$, i.e. the sum of the remaining base year capacity $k_{0}^{i, y, n}$ and newly installed capacity commissioned until the period under consideration $\sum_{z=1}^{y} k^{i, z, n}$ multiplied by availability $a^{n}$, and writes:

$$
\left(k_{0}^{i, y, n}+\sum_{z=1}^{y} k^{i, z, n}\right) a^{n} \geq q^{i, y, n, t, \omega}, \forall y \in Y, n \in N, t \in T, \omega \in \Omega .
$$

A second restriction ensures that new installation does not exceed geographic or political restrictions for the expansion of certain technologies ${ }^{6} \bar{k}^{i, y, n}$, and is given by:

$$
\bar{k}^{i, y, n} \geq k^{i, y, n}, \forall y \in Y, n \in N \text {. }
$$

The restricted optimization problem of firm $i$ can be reformulated as follows:

$$
\begin{aligned}
\max _{q, k} L^{i}= & \sum_{y=1}^{Y}\left(\frac{1}{1+\delta}\right)^{y} \sum_{n=1}^{N} \sum_{t=1}^{T} \sum_{\omega=1}^{\Omega}\left(f ( \omega ) \left(\left(P^{y, t, \omega}\left(X^{y, t, \omega}\right)-C_{q}^{y, n}\right) q^{i, y, n, t, \omega}\right.\right. \\
& \left.+\kappa^{i, y, n, t, \omega}\left(\left(k_{0}^{i, y, n}+\sum_{z=1}^{y} k^{i, z, n}\right) a^{n}-q^{i, y, n, t, \omega}\right)\right) \\
& \left.+\iota^{i, y, n}\left(\bar{k}^{i, y, n}-k^{i, y, n}\right)-F^{n} k^{i, y, n}\right),
\end{aligned}
$$

\footnotetext{
${ }^{6}$ For instance, the possible expansion of gas fired power plants in Poland could be limited by political objections against a further increase of the dependency on Russian gas.
} 
with shadow variables $\kappa^{i, y, n, t, \omega}$ and $\iota^{i, y, n}$ accounting for the restrictions in available capacity and investment feasibility respectively.

The first order conditions of firm $i$ with regard to supply write:

$$
\frac{\partial L^{i}}{\partial q^{i, y, n, t, \omega}}=P^{y, t, \omega}\left(X^{y, t, \omega}\right)-C_{q}^{y, n}-\kappa^{i, y, n, t, \omega} \leq 0, \forall y \in Y, n \in N, t \in T, \omega \in \Omega,
$$

and reflects perfectly competitive supply behavior under capacity restrictions, i.e. the shadow values of the capacity restriction $\kappa$ are equal to marginal profits.

The following first order conditions relate marginal profits to investment costs and define the optimal investment decisions of firm $i$ :

$$
\begin{array}{r}
\frac{\partial L^{i}}{\partial k^{i, y, n}}=\sum_{z=y}^{Y}\left(\frac{1}{1+\delta}\right)^{z} \sum_{t=1}^{T} \sum_{\omega=1}^{\Omega}\left(f(\omega) \kappa^{i, z, t, n, \omega} a^{n}-\iota^{i, y, n}\right)-F^{n} \leq 0, \\
\forall y \in Y, n \in N .
\end{array}
$$

Furthermore, the optimization variables are restricted to be non-negative, and if they are greater than zero, conditions (6) and (7) hold with equality:

$$
q \geq 0, k \geq 0, q \frac{\partial L}{\partial q}=0, k \frac{\partial L}{\partial k}=0
$$

Similar conditions also apply to the shadow variables and corresponding restrictions:

$$
\kappa \geq 0, \iota \geq 0, \frac{\partial L}{\partial \kappa} \geq 0, \kappa \frac{\partial L}{\partial \kappa}=0, \iota \frac{\partial L}{\partial \iota} \geq 0, \iota \frac{\partial L}{\partial \iota}=0 .
$$

Finally, market clearing conditions ensure demand and supply balance, including trade flows and supply of renewable energy $q_{r e s}^{s, y, t, \omega}$.

For the representation of trade flows, the regional index $s$ has to be added. The market clearing conditions can now be written as:

$$
\begin{array}{r}
X^{s, y, t, \omega}\left(P^{s, y, t, \omega}\right)=\sum_{i \in i i(s)} \sum_{n}^{N} q^{i, y, n, t, \omega}-\sum_{s s \neq s}\left(E x^{s, s s, y, t, \omega}-E x^{s s, s, y, t, \omega}\right)+q_{r e s}^{s, y, t, \omega}, \\
\forall s \in S, y \in Y, t \in T, \omega \in \Omega,
\end{array}
$$

where the LHS of (10) is the direct demand function, $i i(s)$ denotes the group of firms in region $s$, and $E x^{s, s s, y, t, \omega}$ denotes an export from region $s$ to region $s s$. The market clearing conditions (10) remain unchanged throughout the model refinements presented in the following sections.

International trade is represented by an optimization problem of traders. More precisely, exports of electricity from region $s$ to region $s s$ are implied by the following 
profit maximization problem of a representative trader:

$$
\begin{aligned}
\max _{E x} \pi= & \sum_{y=1}^{Y} \sum_{t=1}^{T} \sum_{\omega=1}^{\Omega}\left(P^{s s, y, t, \omega}\left(X^{s s, y, t, \omega}\right)-P^{s, y, t, \omega}\left(X^{s, y, t, \omega}\right)-\tau^{s, s s, y, t, \omega}\right) \\
& f(\omega) E x^{s, s s, y, t, \omega}, \forall s s \in S
\end{aligned}
$$

where $E x^{s, s s, y, t, \omega}$ denotes electricity exports from country $s$ to the country of destination $s s$, and $\tau^{s, s s, y, t, \omega}$ is the (scarcity) price of transmission capacity from region $s$ to $s s$, implied by the restricted maximum transmission line capacity $\overline{E x}^{s, s s, y}$ :

$$
\overline{E x}^{s, s s, y} \geq E x^{s, s s, y, t, \omega}, \forall s s \in S, y \in Y, t \in T, \omega \in \Omega .
$$

Taking the derivative of (11) with respect to exports yields the first order optimality with respect to trade:

$$
\begin{array}{r}
\frac{\partial \pi}{\partial E x^{s, s s, y, t, \omega}}=P^{s s, y, t, \omega}\left(X^{s s, y, t, \omega}\right)-P^{s, y, t, \omega}\left(X^{s, y, t, \omega}\right)-\tau^{s, s s, y, t, \omega} \leq 0, \\
\forall s, s s \in S, y \in Y, t \in T, \omega \in \Omega .
\end{array}
$$

Furthermore, optimality requires

$$
\frac{\partial \pi}{\partial \tau} \geq 0, \tau \geq 0, \tau \frac{\partial \pi}{\partial \tau}=0
$$

In conjunction with $(14),(13)$ says that in case of exports the prices of the import country have to cover the prices of the export country plus the scarcity price of transmission capacity. The optimality conditions for trade, (13) and (14), do not change under the different regulations presented in the following.

\section{$2.2 \quad$ Strategic Reserve}

In a system with strategic reserves the regional regulator fixes a target for reliable capacity, and offers a sufficient payment for reserved capacities. These capacities are not allowed to participate in the energy market with the exception of predefined extreme situations. The strategic reserve policy potentially affects the energy market through three channels. First, it may withdraw existing capacities from the energy market under non-extreme situations, thereby raising electricity wholesale prices. Second, it may trigger additional new investment that is used in extreme situations, which dampens the wholesale prices in times of the extreme event. Thirdly, a fee to finance reserve payments is levied from consumers, which tends to reduce electricity demand.

The necessary reserve payments can be determined as the shadow values of appropriate restrictions that ensure the fulfillment of the capacity targets. Let the regulatory chosen target level of available capacity be equal to the forecast peak demand denoted $\bar{Q}_{\text {peak }}^{s, y}$ multiplied by the reserve factor $\alpha$, and $\bar{q}_{r e s}^{s, y}$ denote exogenously supplied reliable capacity of renewable energy. Then the inequality restrictions in- 
duced by the capacity target can be written as

$$
\sum_{i \in i i(s)} \sum_{n=1}^{N}\left(k_{0}^{i, y, n}+\sum_{z=1}^{y} k^{i, z, n}\right) a^{n}+\bar{q}_{r e s}^{s, y} \geq \bar{Q}_{\text {peak }}^{s, y} \alpha, \forall s \in S, y \in Y,
$$

where $i i(s)$ assigns a set of firms to each region. (15) establishes shadow values $\sigma_{\text {stra }}^{s, y}$, which are the necessary reserve payments that trigger sufficient investments into new capacity $\sum_{i \in i i(s)} \sum_{n=1}^{N} k^{i, z, n}$ as described in the optimization of the firms below.

Capacities paid the reserve payment, $\bar{q}_{s r}^{i, y, n}$, are only allowed to be used in the energy market in extreme demand event $\omega^{*}$. In the other demand events the generation restriction of firm $i$ in period $y$ and technology $n$ of the basic model (3) becomes:

$$
\left(k_{0}^{i, y, n}+\sum_{z=1}^{y} k^{i, z, n}\right) a^{n}-\bar{q}_{s r}^{i, y, n}-q^{i, y, n, t, \omega} \geq 0, \forall y \in Y, n \in N, \omega \neq \omega^{*} .
$$

The budget for reserve payments is financed by a fee $\zeta_{s r}^{s, y}$ :

$$
\zeta_{s r}^{s, y}=\frac{\sum_{i \in i i(s)} \sum_{n=1}^{N} \bar{q}_{s r}^{i, y, n} \sigma_{s r}^{s, y}}{\sum_{t=1}^{T} \sum_{\omega=1}^{\Omega} f(\omega) X^{y, t, \omega}} .
$$

The consumer price of electricity therefore becomes $P_{c o n s}^{s, y, t, \omega}=P^{s, y, t, \omega}+\zeta_{s r}^{s, y}$, and corresponds with an adjusted inverse demand faced by suppliers.

Karush-Kuhn-Tucker formulation of the problem yields

$$
\begin{aligned}
\max _{q, \bar{q}_{s r}, k} L^{i}= & \sum_{y=1}^{Y}\left(\frac{1}{1+\delta}\right)^{y} \sum_{n=1}^{N} \sum_{t=1}^{T} \sum_{\omega=1}^{\Omega}\left(f ( \omega ) \left(\left(P^{y, t, \omega}\left(X^{y, t, \omega}\right)-C_{q}^{y, n}\right) q^{i, y, n, t, \omega}\right.\right. \\
& \left.+\kappa^{i, y, n, t, \omega}\left(\left(k_{0}^{i, y, n}+\sum_{z=1}^{y} k^{i, z, n}\right) a^{n}-q^{i, y, n, t, \omega}-\bar{q}_{s r}^{i, y, n}\right)\right)+\sigma_{s r}^{l o c(i), y} \bar{q}_{s r}^{i, y, n} \\
& \left.+\iota^{i, y, n}\left(\bar{k}^{i, y, n}-k^{i, y, n}\right)-F^{n} k^{i, y, n}\right) .
\end{aligned}
$$

The KKT first order conditions of this problem with regard to supply of the representative firm writes

$$
\frac{\partial L^{i}}{\partial q^{i, y, n, t, \omega}}=P^{y, t, \omega}\left(X^{y, t, \omega}\right)-C_{q}^{y, n}-\kappa^{i, y, n, t, \omega} \leq 0, \forall y \in Y, n \in N, t \in T, \omega \in \Omega,
$$

Investment decisions are guided by the first order condition with respect to investments:

$$
\frac{\partial L^{i}}{\partial k^{i, y, n}}=\sum_{z=y}^{Y}\left(\frac{1}{1+\delta}\right)^{z} \sum_{t=1}^{T} \sum_{\omega=1}^{\Omega}\left(f(\omega) \kappa^{i, z, t, n, \omega} a^{n}-\iota^{i, z, n}\right)-F^{n} \leq 0, \forall y \in Y, n \in N
$$


The decision of the firm to sell reliable capacity of technology $n$ as strategic reserve is derived by differentiation of (18) with respect to reserved capacity. This yields

$$
\frac{\partial L^{i}}{\partial \bar{q}_{s r}^{i, y, n}}=-\sum_{t=1}^{T} \sum_{\omega=1}^{\Omega} f(\omega) \kappa^{i, y, n, t, \omega}+\sigma_{s r}^{l o c(i), y} \leq 0, \forall y \in Y, n \in N .
$$

The first order conditions with regard to supply and investment, (18) and (19), are formally identical to the corresponding inequalities in the basic model. However, optimality condition (20) is added and the capacity restriction is amended. Consequently, the operating profit in the energy market, i.e. $\sum_{t=1}^{T} \sum_{\omega=1}^{\Omega} f(\omega) \kappa$, has to match at least the reserve capacity payment.

The remaining optimality conditions of the basic model, particularly (8) and (9), persist. Additionally, optimality requires $\bar{q}_{s r} \geq 0$, and $\bar{q}_{s r} \frac{\partial L}{\partial \bar{q}_{s r}}=0$.

\subsection{Capacity market}

In a regulation with capacity markets, the regional regulator fixes a capacity target and endows all reliable capacity with a sufficient payment. These capacities are only to be held available, and are not subject to any control of performance. The capacity market considered here simply induces more capacity on the market and consequently reduces the electricity wholesale prices, while it establishes a second stream of income for reliable units. In addition, a fee to finance capacity payments is levied from consumers.

The necessary capacity payments can be derived as shadow values of restrictions that ensure the fulfillment of the capacity targets. Let the reliable capacities of renewables $\bar{q}_{r e s}^{s, y}$ be exogenously given, and the capacity target be the forecast peak load $\bar{Q}_{\text {peak }}^{s, y}$ multiplied by the system reserve factor $\alpha$, the capacity market can be expressed as the following market clearing condition of fixed capacity demand and capacity supply from regional firms:

$$
\sum_{i \in i i(s)} \sum_{n=1}^{N} q_{c m}^{i, y, n}+\bar{q}_{r e s}^{s, y} \geq \bar{Q}_{\text {peak }}^{s, y} \alpha, \forall s \in S, y \in Y
$$

with $i i(s)$ denoting the set of firms that are located in region $s$. The capacity market clearing condition (21) induces a corresponding shadow variable $\sigma_{c m}^{s, y}$, which are equal to the necessary equilibrium capacity prices included in the optimization of the firms below.

Under this regulation the firms' capacity sales, $q_{c m}$, are restricted to its available 
capacities, leading to the following inequality restrictions:

$$
\sum_{z=1}^{y}\left(k^{i, z, n}+k_{0}^{i, y, n}\right) a^{n} \geq q_{c m}^{i, y, n}, \forall y \in Y, n \in N,
$$

where the LHS of (22) is the sum of available remaining base year capacity and available new built capacity until period $y$. (22) induces shadow variable $\lambda^{i, y, n}$, which reflects the restriction to sell only available capacity on the capacity market.

The budget for capacity payments is financed through a fee, $\zeta_{c m}^{s, y}$, charged on top of the electricity producer price:

$$
\zeta_{c m}^{s, y}=\frac{\left(\sum_{i \in i i(s)} \sum_{n=1}^{N} q_{c m}^{i, y, n}+\bar{q}_{r e s}^{s, y}\right) \sigma_{c m}^{s, y}}{\sum_{t=1}^{T} \sum_{\omega=1}^{\Omega} f(\omega) X^{y, t, \omega}} .
$$

The consumer price of electricity is therefore $P_{c o n s}^{s, y, t, \omega}=P^{s, y, t, \omega}+\zeta_{c m}^{s, y}$, which modifies the inverse demand in case of a capacity market.

The Karush-Kuhn-Tucker formulation of the problem of a regional firm can now be written as

$$
\begin{aligned}
\max _{q, q_{c m}, k} L^{i}= & \sum_{y=1}^{Y}\left(\frac{1}{1+\delta}\right)^{y} \sum_{n=1}^{N} \sum_{t=1}^{T} \sum_{\omega=1}^{\Omega}\left(f ( \omega ) \left(\left(P^{y, t, \omega}\left(X^{y, t, \omega}\right)-C_{q}^{y, n}\right) q^{i, y, n, t, \omega}\right.\right. \\
& \left.+\kappa^{i, y, n, t, \omega}\left(\left(k_{0}^{i, y, n}+\sum_{z=1}^{y} k^{i, z, n}\right) a^{n}-q^{i, y, n, t, \omega}\right)\right) \\
& +\lambda^{i, y, n}\left(\left(k_{0}^{i, y, n}+\sum_{z=1}^{y} k^{i, z, n}\right) a^{n}-q_{c m}^{i, y, n}\right) \\
& \left.+\sigma_{c m}^{l o c(i), y} q_{c m}^{i, y, n}+\iota^{i, y, n}\left(\bar{k}^{i, y, n}-k^{i, y, n}\right)-F^{n} k^{i, y, n}\right) .
\end{aligned}
$$

The KKT first order conditions of this problem with regard to supply of a price taking firm are:

$$
\frac{\partial L^{i}}{\partial q^{i, y, n, t, \omega}}=P^{y, t, \omega}\left(X^{y, t, \omega}\right)-C_{q}^{y, n}-\kappa^{i, y, n, t, \omega} \leq 0, \forall y \in Y, n \in N, t \in T, \omega \in \Omega,
$$

and, thus, identical to the according conditions (6) in the basic model.

Investment decisions are guided by the following first order conditions:

$$
\begin{array}{r}
\frac{\partial L^{i}}{\partial k^{i, y, n}}=\sum_{z=y}^{Y}\left(\frac{1}{1+\delta}\right)^{z} \sum_{t=1}^{T} \sum_{\omega=1}^{\Omega}\left(f(\omega) \kappa^{i, z, t, n, \omega} a^{n}+\lambda^{i, z, n} a^{n}-\iota^{i, z, n}\right)-F^{n} \leq 0, \\
\forall y \in Y, n \in N .
\end{array}
$$


Capacity sales to the capacity market are determined by

$$
\frac{\partial L^{i}}{\partial q_{c m}^{i, y, n}}=\sigma_{c m}^{l o c(i), y}-\lambda^{i, z, n} \leq 0, \forall y \in Y, n \in N
$$

Inequality (26) says that the shadow variable of the capacity sales restriction is at least as large as the capacity price.

Since no real costs are involved, the regulation induces a complete sale of available capacities on the capacity market with according additional revenues for all available capacity. In addition to the above conditions and the persisting conditions of the basic model, particularly (8) and (9), optimality requires furthermore: $q_{c m} \geq 0$, $q_{c m} \frac{\partial L}{\partial q_{c m}}=0, \frac{\partial L}{\lambda} \geq 0, \lambda \geq 0$, and $\lambda \frac{\partial L}{\lambda}=0$.

\subsection{Reserve obligations with tradable capacity certificates}

In a regulation with reserve obligations the regulator prescribes suppliers to guarantee firm capacity that establishes a reserve factor in relation to their peak supply under not extreme demand events. Under regulatory defined extreme demand events these reserves are free to supply. If firms are allowed to fulfill their capacity obligation either through sufficient own capacity reserves or through the purchase of certified capacity and if firms have different opportunity costs to fulfill their reserve obligation, the regulation will induce a market for certified firm capacity.

Market clearing on the capacity certificate market of region $s$ can be expressed as the equalization of the sum of certificate sales, $z_{s}^{i, y, t, \omega}$, and certificate purchases, $z_{p}^{i, y, t, \omega}$, of regional conventional suppliers $i i(s)$ and the sum of certificate sales created by renewable energy, $z_{r e s}^{s, y, t, \omega}$, and net exports, $z_{x}^{s, y, t, \omega}$. Denoting the extreme demand event with $\omega^{*}$, the balance on the capacity certificate market can be expressed as:

$$
\sum_{i \in i i(s)}\left(z_{s}^{i, y, t, \omega}-z_{p}^{i, y, t, \omega}\right)+z_{\text {res }}^{s, y, t, \omega}+z_{x}^{s, y, t, \omega}=0, \forall s \in S, y \in Y, t \in T, \omega \in \Omega, \omega \neq \omega^{*},
$$

which determines regional certificate prices $\sigma^{s, y, t, \omega}$ in normal demand events. Certificate sales of renewable energy are exogenously given, while certificate sales from exports are determined by the international price differences and certificate sales and purchases of conventional firms are implicitly given by the additionally restricted optimization described in the following.

The regulation requires the firms to hold reliable capacity or certificates of reliable capacity that cover their own peak supply in not extreme demand events at least with the reserve factor $\alpha$. Representative firm $i$ 's decisions are thus restricted by

$z_{s}^{i, y, t, \omega}-z_{p}^{i, y, t, \omega} \leq \sum_{n}\left(k_{0}^{i, y, n}+\sum_{z=1}^{y} k^{i, z, n}\right) a^{n}-\alpha \sum_{n} q^{i, y, n, t, \omega}, \forall y \in Y, t \in T, \omega \in \Omega, \omega \neq \omega^{*}$,

which guarantees that net certificate sales are not greater than reliable capacity in 
excess of the requirement. (28) induces firm specific shadow prices $\mu^{i, y, t, \omega}$ in not extreme demand events.

Net imports to country $s, \sum_{s s \in S} E x^{s s, s, y, t, \omega}-E x^{s, s s, y, t, \omega}$, and inelastic supply from renewable energy sources (RES) denoted $q_{r e s}^{s, y, t}$ create additional certificates $z_{x}^{s}$ and $z_{\text {res }}^{s}$. However, these supplies take the price for capacity as given. Consequently, their supply of certificates can be described by the following equalities. Certificate supply related to net export is

$$
z_{x}^{s, y, t, \omega}=\alpha \sum_{s s \in S}\left(E x^{s, s s, y, t, \omega}-E x^{s s, s, y, t, \omega}\right) .
$$

RES create certificate supply according to their inelastic output and their reliable capacity $\bar{q}_{r e s}^{s, y}$ :

$$
z_{\text {res }}^{s, y, t, \omega}=\bar{q}_{r e s}^{s, y}-\alpha q_{r e s}^{s, y, t, \omega} .
$$

The problem of the conventional firm can now be stated as a problem of the KarushKuhn-Tucker type as follows:

$$
\begin{aligned}
\max _{q, z_{s}, z_{p}, k} L^{i}= & \sum_{y=1}^{Y}\left(\frac{1}{1+\delta}\right)^{y} \sum_{n=1}^{N}\left(\sum _ { t = 1 } ^ { T } \sum _ { \omega = 1 } ^ { \Omega } f ( \omega ) \left(P^{y, t, \omega}\left(X^{y, t, \omega}\right)\left(X^{y, t}\right) q^{i, y, n, t, \omega}-C_{q}^{y, n} q^{i, y, n, t, \omega}\right.\right. \\
& +\kappa^{i, y, n, t, \omega}\left(\left(k_{0}^{i, y, n}+\sum_{z=1}^{y} k^{i, z, n}\right) a^{n}-q^{i, y, n, t, \omega}\right)+\sigma^{s, y, t, \omega}\left(z_{s}^{i, y, t, \omega}-z_{p}^{i, y, t, \omega}\right) \\
& \left.+\mu^{i, y, t, \omega}\left(\left(k_{0}^{i, y, n}+\sum_{z=1}^{y} k^{i, z, n}\right) a^{n}+z_{p}^{i, y, t, \omega}-z_{s}^{i, y, t, \omega}-\alpha q^{i, y, n, t, \omega}\right)\right) \\
& \left.+\iota^{i, y, n}\left(\bar{k}^{i, y, n}-k^{i, y, n}\right)-F^{n} k^{i, y, n}\right)
\end{aligned}
$$

Deriving the KKT conditions of this problem with regard to supply of firm $i$ we get:

$$
\frac{\partial L^{i}}{\partial q^{i, y, n, t, \omega}}=P^{y, t, \omega}\left(X^{y, t, \omega}\right)-C_{q}^{y, n}-\kappa^{i, y, n, t, \omega}-\mu^{i, y, t, \omega} \alpha \leq 0, \forall y \in Y, n \in N, t \in T, \omega \in \Omega .
$$

The conditions (32) show that the firm treats the additional requirement induced by an additional supply like an additional cost, i.e it deducts the shadow variable of its capacity requirement weighted with the reserve factor from marginal revenues.

The KKT first order conditions with regard to investment can be written as

$$
\begin{array}{r}
\frac{\partial L^{i}}{\partial k^{i, y, n}}=\sum_{z=y}^{Y}\left(\frac{1}{1+\delta}\right)^{z} \sum_{t=1}^{T} \sum_{\omega=1}^{\Omega}\left(f(\omega)\left(\kappa^{i, z, t, n, \omega}+\mu^{i, z, t, \omega}\right) a^{n}-\iota^{i, z, n}\right)-F^{n} \leq 0, \\
\forall y \in Y, n \in N,
\end{array}
$$


Certificate sales are guided by the following inequalities:

$$
\frac{\partial L^{i}}{\partial z_{s}^{i, y, t, \omega}}=\sigma^{s, y, t, \omega}-\mu^{i, y, t, \omega} \leq 0, \forall y \in Y, t \in T, \omega \in \Omega
$$

The certificate purchase decisions are ruled by an inequality that is equivalent to (34) up to a change in signs of the terms:

$$
\frac{\partial L^{i}}{\partial z_{p}^{i, y, t, \omega}}=-\sigma^{s, y, t, \omega}+\mu^{i, y, t, \omega} \leq 0, \forall y \in Y, t \in T, \omega \in \Omega,
$$

Additionally, the following conditions have to hold: $z \geq 0, z \frac{\partial L}{\partial z}=0, \frac{\partial L}{\mu} \geq 0, \mu \geq 0$, and $\mu \frac{\partial L}{\mu}=0$. In combination with these additional conditions, inequalities (34) and (35) show that when the firm trades in the capacity certificate market, it sets the shadow price of its specific capacity requirement $\mu$ equal to the capacity price $\sigma$. Since the capacity price is only greater zero if the capacity requirement is binding, it follows that the firms supply decision described in (32) is impacted by the regulation only in peak load situations.

Finally, optimality conditions, particularly (8) and (9), of the basic model persist, while the optimal trade flows are based on prices net of certificate purchases. For all $s, s s$ the prices $P^{s, y, t, \omega}$ in (13) are replaced by $P_{\text {prod }}^{s, y, t, \omega}=P^{s, y, t, \omega}-\sigma^{s, y, t, \omega} \alpha$. Thus I assume that exports are not burdened by the capacity certificate prices of the country of origin.

\section{Scenarios and Data}

The model is applied to the development of the interconnected electricity markets of Germany (De), France (Fr), and Poland (Pl) based on calculations for reference years 2023 and 2033. For investment incentives each represented year forms the basis of the calculation of ten consecutive years of electricity market revenues. The years are furthermore represented by three load days with 24 hourly time steps of price and consumption combinations. Comparability of the three policies "Energy Only Market" (EOM), "Strategic Reserve" (SR), "Capacity Market" (CM), and "Reserve Obligation with Capacity Certificate Market" (RM) is achieved by the assumption of a common reserve margin of five percent excess firm capacity compared to the load peak.

Denoting reference demand with $D 0^{s, t, \omega}$ and reference prices $P 0^{s, t, \omega}$, demand is represented by hourly linear demand functions of the form

$$
D^{s, y, t, \omega}\left(P^{s, y, t, \omega}\right)=\quad D 0^{s, t, \omega}+D 0^{s, t, \omega}\left(1-\frac{P^{s, y, t, \omega}}{P 0^{s, t, \omega}}\right)\left|\epsilon_{0}\right|,
$$

where $\epsilon_{0}$ is the assumed elasticity of demand at the reference point. In order to investigate the robustness of the implications of different policy settings we use two scenarios: A high elasticity scenario with reference elasticity of -0.4 and a low 
elasticity scenario with reference elasticity -0.2 .

For the reference demand and price values, we adopt consumption data from ENTSO-E ${ }^{7}$, and wholesale prices for the year 2010. Total combined load of the three countries has been used to construct three seasons as a basis for three representing load days: a winter season with a 26.6 percent annual frequency, a shoulder season for autumn and spring with 25.8, and a low-load summer season with a 47.7 percent frequency. In combination with the availability of renewable energy these demand situations form the basis of the four load events represented in the model: winter (s1), shoulder (s2), summer (s3), and winter with low wind energy supply (s4). This latter event corresponds to a winter demand situation with only a sixth of the seasonal winter wind availability documented below with an assigned frequency of 0.3 percent. The reference spot market prices are constructed from the according time intervals based on POLPX $^{8}$ and EPEX ${ }^{9}$ dayahead spotmarket data that show in average wholesale prices in 2010 of 44 Euro per MWh in Germany and France (both EPEX) and 46 in Poland (POLPX).

The demand data has been furthermore scaled up by 5, 15 and 10 percent for Germany, France and Poland respectively to match total annual reference demand of 562 TWh in Germany, 590 TWh in France, and 170 TWh in Poland in $2023^{10}$. For the representation of the development until 2033, the reference demand is further increased by a factor of 1.05 for France and Germany, and a factor of 1.1 for Poland.

In this model framework renewable energy supplied by solar, wind and biomass units is exogenous, and generators face a residual demand net of these supplies. Solar, wind and biomass supply is based on the development of their installed capacities and their assumed supply profiles: While biomass supply is assumed to be constant over time, wind and solar supply is based on time profiles of German wind and solar power production in the three demand seasons introduced previously. To get typical daily profiles, seasonal and hourly availability of wind power data from 2006 until 2012 has been averaged ${ }^{11}$. Photovoltaic power profiles are based only on data from the years 2011 and 2012, which is not problematic since it shows only much less pronounced seasonal differences in different years. The basic supply profiles imply averaged annual utilization rates of 27.0 percent for wind power, and 10.8 percent for solar power plants.

\footnotetext{
${ }^{7}$ This data is available at the ENTSO-E data portal, https://www.entsoe.eu/data/dataportal/consumption/. The German ENTSO-E values do not include industrial own consumption and parts of the consumption of railways, adding at average 8.5 percent.

${ }^{8}$ Polish Power Exchange.

${ }^{9}$ European Power Exchange.

${ }^{10}$ The German value corresponds to the value of the Network Development Plan 2013 ÜNB (2013b) with additional five percent assumed grid losses. French demand data is based on the Median scenario of the French Generation adequacy report RTE (2013), and the estimate for Poland assumes a ten percent increase in the current decade and is derived in accordance with the development of the Polish peak load as laid out in the demand prognosis ARE (2011) for the Polish ministry of economy

${ }^{11}$ Seasonal wind power looses the major part of its variability when using average values. However, wind variability and its impacts are not the focus of this study and investment incentives are considered to be impacted by variability only to a minor extent.
} 


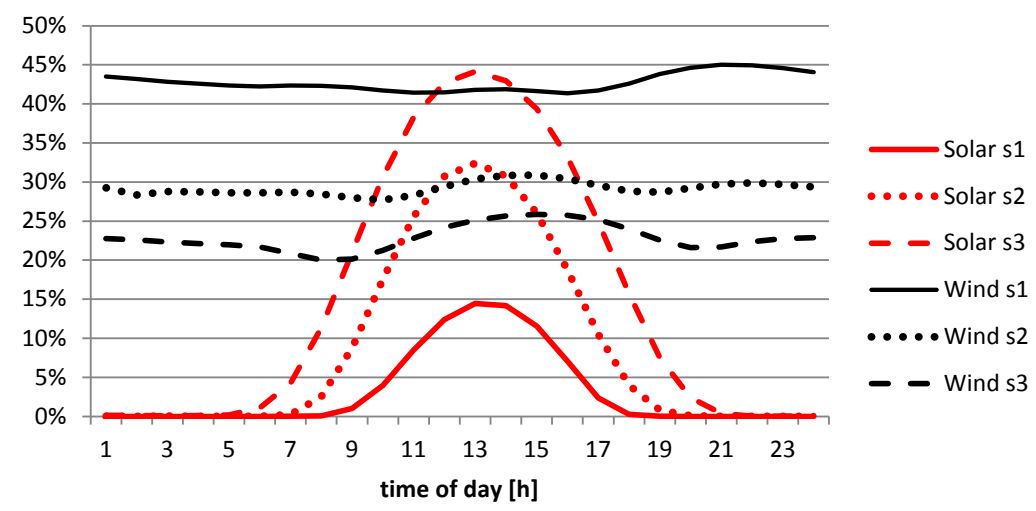

Figure 1: Hourly seasonal wind and solar supply profiles in the seasons winter s1, shoulder s2 and summer s3 for Germany.

For Germany these profiles of wind and solar power are scaled to reach the annual utilization rates of 29.7 percent for wind power and 10.2 for solar power implied by the output and capacities for the year 2023 of scenario B in the German ÜNB (2013b). The profiles are laid out to exemplify the used hourly capacity factors in the three seasons s1 to s3 in Figure 1. They show how wind power and solar power complement each other in the sense that their dominant supply seasons are inversely related: The windy winter season with an average availability of forty three percent corresponds to a poor solar power performance with an average availability of three percent, while in sunny summer solar has an average availability of sixteen percent and wind has only little more than half of its winter performance ( 23 percent).

The basic profiles are also used for the assumed hourly supply profiles of wind and solar in Poland and France, which are further scaled to match the capacity factors implied by the figures in the National Renewable Energy Action Plans (NREAPs) published in Beurskens and Hekkenberg (2011). These capacity factors are 26.4 percent for French, and 26.1 percent for Polish wind power respectively, which are achieved with scaling factors of 98 and 97 percent.

The generation of biomass power is based on a annual availability factor of 64 percent implied by ÜNB (2013b). This availability is assumed for all countries since factors for Poland and France as given implicitly by capacities and generation of the NREAP do not notably deviate from this value. By contrast, average annual availabilities of hydro power show substantial differences across countries in line with the NREAPs for the year 2020, i.e. 53, 31 and 29 percent for German, French, and Polish generators respectively. Differing from the treatment of the other renewable energy sources hydro power supply itself is, however, calculated endogenously as a market decision and pumped hydro power supply is not considered.

Apart from energy, the renewable plants provide also significant reliable capacities, which is of special interest in the context of capacity mechanisms. We adopt reliability factors identical with average availabilities in case of biomass power plants. In regard to the fluctuating renewable energy sources wind and solar, reliability is strongly influenced by fluctuations under different meteorological conditions. This significantly reduces the reliability factor compared to average availability. For wind 
and solar we adopt 1 and 0 percent respectively in line with assumptions of the report of the German transmission system operators (ÜNB (2013a)). Renewable hydro power reliability is set in accordance with their country availabilities documented in the previous paragraph, whereas the provision of reliable capacity of pumped hydro storage is rated at 80 percent. The underlying hydro power capacities are based on Platts power plant database 2012 and data provided by ENTSO-E in the scenario outlook and adequacy forecast 2013-2030. As shown in Table 1, reliable capacities of renewable energies including pumped hydro storage in Germany amount to 13.8 GW by 2023 and 15.3 GW by 2033, where around 39 and more than 55 percent are provided by biomass and hydro capacities respectively. In France hydro power delivers more than two thirds of reliable renewable energy capacity, whereas in Poland biomass is the dominating source.

The assessment of existing thermal generation capacities is based on information of Platts power plant database 2012 and minor own updates. These capacities are assumed to be decommissioned after a lifetime of 40 years in case of gas turbines (Gas GT, Oil GT), and 50 years in case of steam turbines (Lignite, Hard Coal, Gas, Oil) or combined cycle gas turbines (Gas CC). Furthermore, nuclear power plants in Germany are phased out completely, while a lifetime of 45 years for French nuclear power plants is adopted in correspondence with an governmental announcement to reduce the share of nuclear power to fifty percent by 2025. Table 1 shows reliable thermal capacities. In Germany remaining reliable capacity sums up to $73.1 \mathrm{GW}$ by the year 2023 and $58.0 \mathrm{GW}$ by the year 2033, implying a reduction of 21 percent in that decade. The corresponding values for France and Poland are 48 and 28 percent respectively, and are dominated by reduction of French nuclear power by 71 percent and of Polish hard coal power plants by 53 percent.

\begin{tabular}{|c|c|c|c|c|c|c|c|c|c|}
\hline & Year & |Country & clear & & ard Coal & as CC & |Gas/Oil ST/GT & |Renewables & |Total \\
\hline \multirow{6}{*}{ 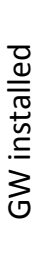 } & & $\mathrm{De}$ & 0,0 & 16,9 & 26,3 & 14,3 & 11,3 & 144,4 & 213,0 \\
\hline & 2023 & $\overline{F r}$ & 61,2 & 0,0 & 3,3 & 5,3 & 4,3 & 66,5 & 140,6 \\
\hline & & $\overline{\mathrm{Pl}}$ & 0,0 & 6,7 & 18,1 & 1,3 & 0,4 & 13,9 & 40,4 \\
\hline & & $\mathrm{De}$ & 0,0 & 11,4 & 20,0 & 13,6 & 4,6 & 178,2 & 227,7 \\
\hline & 2033 & $\mathrm{Fr}$ & 17,6 & 0,0 & 2,7 & 5,3 & 3,8 & 92,8 & 122,3 \\
\hline & & $\mathrm{Pl}$ & 0,0 & 6,0 & 8,4 & 1,3 & 0,2 & 21,6 & 37,6 \\
\hline \multirow{6}{*}{$\begin{array}{l}\frac{0}{0} \\
\frac{.0}{0} \\
\frac{0}{0} \\
\sum_{0}^{2}\end{array}$} & & $\mathrm{De}$ & 0,0 & 14,4 & 21,5 & 13,2 & 10,2 & 13,8 & 73,1 \\
\hline & 2023 & $\overline{F r}$ & 49,6 & 0,0 & 2,7 & 4,9 & 3,9 & 11,3 & 72,4 \\
\hline & & $\mathrm{Pl}$ & 0,0 & 5,7 & 14,8 & 1,2 & 0,3 & 3,6 & 25,7 \\
\hline & & $\mathrm{De}$ & 0,0 & 9,7 & 16,4 & 12,5 & 4,2 & 15,3 & 58,0 \\
\hline & 2033 & $\overline{F r}$ & 14,3 & 0,0 & 2,2 & 4,9 & 3,5 & 12,8 & 37,7 \\
\hline & & $\overline{\mathrm{Pl}}$ & 0,0 & 5,1 & 6,9 & 1,2 & 0,2 & 5,0 & 18,4 \\
\hline
\end{tabular}

Table 1: Exogenous power plants by 2023 and 2033 in GW installed (top) and reliable (bottom) capacity.

We consider investment in new gas combined cycle (CC), new gas fired gas turbines (Gas GT), new hard coal power plants (Hard Coal new) and the retrofit of old gas and oil fired units. The potential for retrofitting in a given period is derived from the age-based decommissioning of gas and steam turbines using oil or gas in the preceding decade. The same procedure is used to restrict investment in coal 
fired power plants ${ }^{12}$.

Table 2 shows assumptions regarding costs of investments for these technologies together with the essential technology characteristics in regard to efficiency, operation and maintenance (O\&M), emissions and availabilities also of existing technologies. These parameters are assumed to be constant over the assessed time horizon. Concerning investment and O\&M costs our assumptions are based on the proposal of a data set for electricity market modeling by Schröder et al. (2013). However, since the decision to incur fixed O\&M costs is taken in an intermediate time perspective between investment and dispatch it is not modeled here. For the representation of fixed O\&M costs, we therefore include ten years of discounted fixed O\&M costs in the investment costs in case of new thermal power plants, while in case of hydro power fixed O\&M costs are included in variable O\&M costs. However, fixed O\&M costs for old thermal power plants are excluded. Furthermore, a discount rate of eight percent annually is used for the discounting of revenues from electricity supply over the model periods, where the second model period is calculated to cover a salvage value through an increased weighting of 150 percent ${ }^{13}$. Schröder et al. (2013))

\begin{tabular}{|c|c|c|c|c|c|}
\hline & $\begin{array}{l}\text { Investment } \\
\text { [Mio. Euro/MW] }\end{array}$ & $\begin{array}{l}\text { O\&M } \\
\text { [Euro/MWh] }\end{array}$ & \begin{tabular}{|l} 
Efficiency \\
{$[\%]$}
\end{tabular} & $\begin{array}{l}\mathrm{CO}_{2} \\
{[\mathrm{t} / \mathrm{MWh}]}\end{array}$ & $\begin{array}{l}\text { Availability } \\
{[\%]}\end{array}$ \\
\hline Nuclear & & 10 & 33 & 0,0 & 81 \\
\hline Lignite & - & 7 & 41 & 1,0 & 85 \\
\hline Hard Coal & & 6 & 42 & 0,8 & 82 \\
\hline Hard Coal new & 1,5 & 6 & 46 & 0,8 & 82 \\
\hline Gas CC & 0,9 & 3 & 60 & 0,3 & 92 \\
\hline Gas ST & & 3 & 42 & 0,5 & 90 \\
\hline Gas GT & 0,5 & 3 & 33 & 0,6 & 92 \\
\hline Oil ST & 1 & 3 & 40 & 0,7 & 90 \\
\hline Oil GT & - & 3 & 32 & 0,9 & 90 \\
\hline Gas Retrofit & 0,4 & 3 & 44 & 0,5 & 92 \\
\hline Hydro & & 6 & 100 & 0,0 & $53^{*}$ \\
\hline
\end{tabular}

*Value for German plants; France: 32, Poland: 29.

Table 2: Investment, O\&M costs, degrees of efficiency, emission factors and availabilities.

also propose the documented efficiency degrees for new built power plants. The outlined values for existing coal fired plants are taking age and technological development into account and are therefore a few percentage points below the efficiencies of the respective new built plants. Referenced emissions per output are based on these efficiencies and on standard fuel emission factors. The documented average annual availability factors including planned and unplanned outages refer to VGB (2012) and have been used to calculate reliable available capacities that are laid out

\footnotetext{
${ }^{12}$ This assumption can be considered as mild since it turns out to be non binding in the scenarios we investigate.

${ }^{13}$ The corresponding fifty percent increase of the weighting of the last period is almost equivalent to a repetition of the second model period of ten years starting in 2043.
} 
in the previous table. Cost relevant parameters used for the model are completed

\begin{tabular}{c|r|r|r|r|r|r}
\hline & Nuclear & Lignite & Hard Coal & Natural Gas & Oil & $\mathrm{CO}_{2}$ \\
\cline { 2 - 7 }$€$ & \multicolumn{5}{|c|}{ per MWh } & per ton \\
\hline 2023 & 6.0 & 1.5 & 9.7 & 26.0 & 51.2 & 25 \\
2033 & 7.0 & 1.5 & 10.6 & 27.0 & 55.1 & 35 \\
\hline
\end{tabular}

Table 3: Input fuel and emission prices by 2023 and 2033

by the assumptions of the NEP (2013) regarding the increase of fuel and emission prices by 2023 and 2033, and are documented in table 3. Based on these values, we get marginal costs of generation from existing hard coal of 50 and 60 Euro per MWh and from CC plants of 55 and 60 Euro per MWH in the periods 2023 and 2033 respectively.

Finally, international electricity flows are restricted by an average of the net transfer capacities that are published by ENTSOE (ENTSOE (2011a), ENTSOE (2011b)) and are summed over all interconnectors between each pair of countries. These values are kept constant over the considered periods.

\section{Results}

First, we summarize results for the basic energy only market regulation and present policy effects on the three coupled central European markets in Germany, France and Poland. Second, we provide a more detailed analysis of the German market with in depth explanation of important drivers.

\subsection{Central Europe}

Table 4 shows model results for EOM including average prices, profit, and consumer rent for the three countries. More precisely, we compute profit as difference between revenues and costs of production including costs of new investment in conventional capacities $^{14}$, whereas the consumer rent (CR) is calculated as the difference of the willingness to pay of consumers, - implied by the inverse demand curve -, and the market clearing price.

For Germany we simulate average prices of about 50 Euro per MWh by 2023 and of about 60 Euro by 2033. Respective prices for France are found to be about ten Euro lower by 2023 and about ten Euro higher by 2033, whereas the Polish average prices are close to the results for Germany. Compared with the reference prices of

\footnotetext{
${ }^{14}$ We do not consider costs of renewable energy investments, since these are implicitly fixed by country targets and do not change in our investigated scenarios. Moreover, costs of capital of existing capacities is not taken into account. This value is assumed to be independent of the implemented policy.
} 


\begin{tabular}{|c|c|c|c|c|c|}
\hline & \multicolumn{2}{|c|}{2023} & \multicolumn{2}{|c|}{2033} \\
\hline & & 0.2 & 0.4 & 0.2 & 0.4 \\
\hline \multirow{3}{*}{$\begin{array}{c}\text { Price } \\
{[€ / \mathrm{MWh}]}\end{array}$} & De & 50.7 & 49.8 & 61.2 & 59.0 \\
\hline & $\mathrm{Fr}$ & 42.9 & 42.5 & 70.2 & 69.3 \\
\hline & $\mathrm{PI}$ & 50.1 & 50.2 & 66.0 & 62.0 \\
\hline \multirow{3}{*}{$\begin{array}{c}\text { Profit } \\
{[\text { Bio } € / a]}\end{array}$} & De & 16.7 & 16.4 & 24.2 & 23.2 \\
\hline & $\mathrm{Fr}$ & 13.8 & 13.4 & 21.3 & 21.1 \\
\hline & $\mathrm{PI}$ & 2.7 & 2.7 & 5.6 & 4.9 \\
\hline \multirow{3}{*}{$\begin{array}{c}\text { CR } \\
{[\text { Bio } € / a]}\end{array}$} & $\mathrm{De}$ & 60.9 & 29.5 & 60.8 & 27.2 \\
\hline & $\mathrm{Fr}$ & 66.9 & 34.0 & 57.2 & 22.0 \\
\hline & $\mathrm{PI}$ & 19.1 & 9.3 & 18.0 & 8.1 \\
\hline
\end{tabular}

Table 4: EOM: Average wholesale prices, profits and consumer rent (CR) in Germany, France and Poland by 2023 and 2033 for low (0.2) and high (0.4) elasticity in Euro per MWh.

the year $2010^{15}$, we find average annual electricity prices increasing towards 2023 in Germany and Poland, and decreasing in France as documented in Table 4. The impact of the elasticity assumption on average annual prices is found to be of minor importance by 2023 and shows an maximum price effect of less than one Euro on the German market. By 2033 elasticities play a slightly more prominent role particularly for the Polish market with an induced difference of average prices of four Euro per MWh.

The comparison of average simulated wholesale prices with the marginal costs of conventional generation implied by our cost assumptions shows that average margins of gas and hard coal power plants are almost negligible. Thus, only lignite power in Germany and Poland as well as remaining nuclear plants in France generate significant margins that contribute to the profits laid out in Table 4. These are used as a basis for comparison of policy effects in the following.

We find for the first period annual profits of around 16.5 billion Euro in Germany, more than 13 billion Euro in France and almost 3 billion Euro in Poland with comparatively minor variation induced by the elasticity. These profits increase towards the second period by between 40 and 100 percent, since the importance of renewable sources with negligible variable costs grows considerably. However, the variation of profit due to a change of the elasticity assumption remains on a comparatively low level and exceeds only in Poland ten percent. By contrast, consumer rents are highly depending on the assumed elasticity. For instance in Germany consumer rents in 2023 are calculated to amount to more than 60 billion Euro in case of an assumed low elasticity and less than half of that (29.5 billion Euro) in case of the higher elasticity assumption.

As implication of comparatively low wholesale prices, power plant investment under EOM regulation by 2023 on top of renewable energy expansion is not profitable.

\footnotetext{
${ }^{15}$ Reference prices are 44 Euro per MWh in Germany and France, and 46 Euro per MWh in Poland as documented in the data section.
} 
The picture changes towards 2033 only on the French market, where significant investments are driven by the projected EOM market price development. For that period the model shows more than $24.4 \mathrm{GW}$ of investment in gas fired combined cycle power plants (CC) and about $0.5 \mathrm{GW}$ of retrofitted capacities in case of the lower elasticity, and $11 \mathrm{GW}$ of new CC plant capacity for a higher elasticity. Thus, investments in new thermal power plants are in the long term highly depending on the future responsiveness of the consumers to price changes. Clearly, in the EOM framework under both elasticities we get firm capacities that do not provide a reliability margin against peak demand.

The effects induced by the three policy instruments vary by the assumed demand elasticity, period, and additionally between producers and consumers, if a capacity market or strategic reserve policy with financing fees is introduced. By contrast, no differentiation between market participants is induced by the RM policy since no financing fee has to be levied.

Country conditions play a similarly important role. Figure 2 shows the effects on consumer and producer prices by 2023 for the high (0.2) and the low (0.4) elasticity scenario. Consumer price effects vary from 0.3 Euro per MWh in France under RM-Policy with high elasticity to 7.0 Euro per MWh in Poland under CM-policy with high elasticity. Wholesale producer price effects are also largely depending on the instrument and the country characteristics. The introduction of the CM-Policy depresses wholesale prices in 2023 by up to 6.8 Euro per MWh in France under high elasticity, whereas the SR-policy increases prices by up to 3.7 Euro per MWh in case of Germany under an assumed low elasticity. The RM-policy has comparably modest impacts of between 2.1 and 2.7 Euro per MWh. Towards 2033, price effects

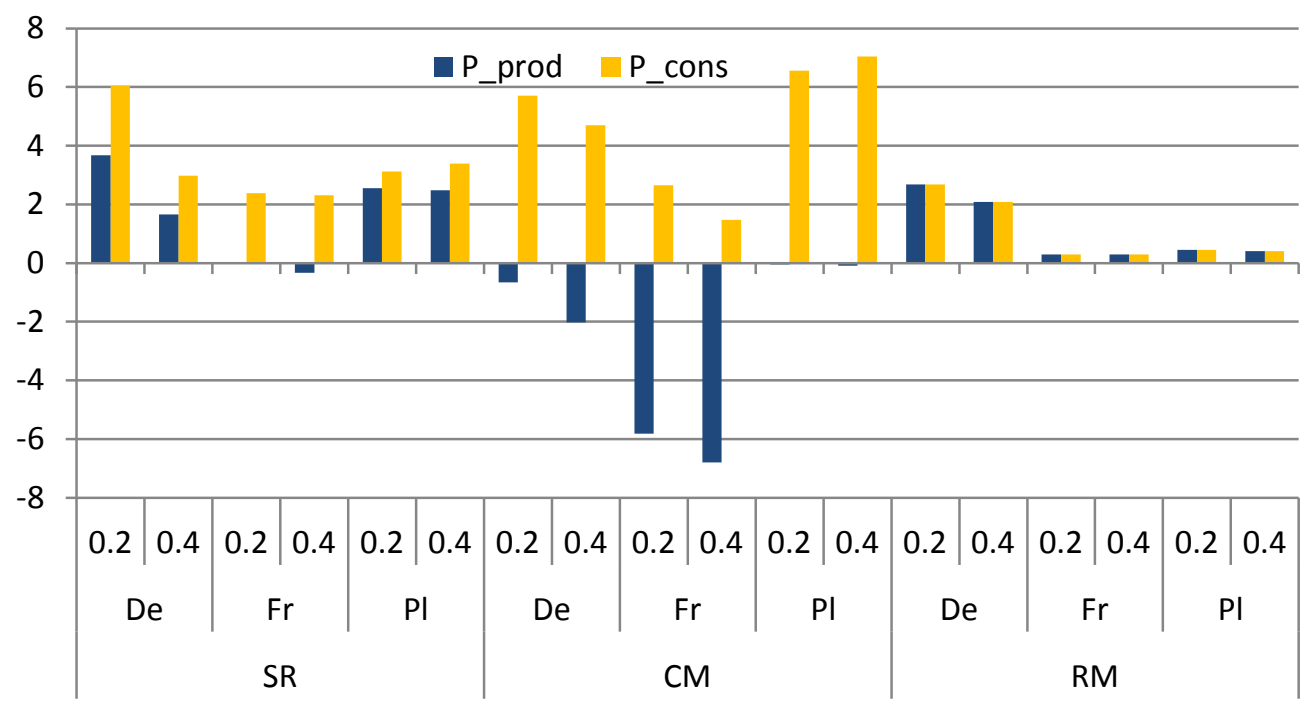

Figure 2: Policy effects on consumer and producer prices in Euro per MWh by 2023 for low (0.2) and high (0.4) elasticity.

for both consumers and producers tend to increase, but show a similar variability across countries and policies as documented in Figure 3. Only the wholesale price dampening effect of the CM-policy in France is found to be significantly reduced, 


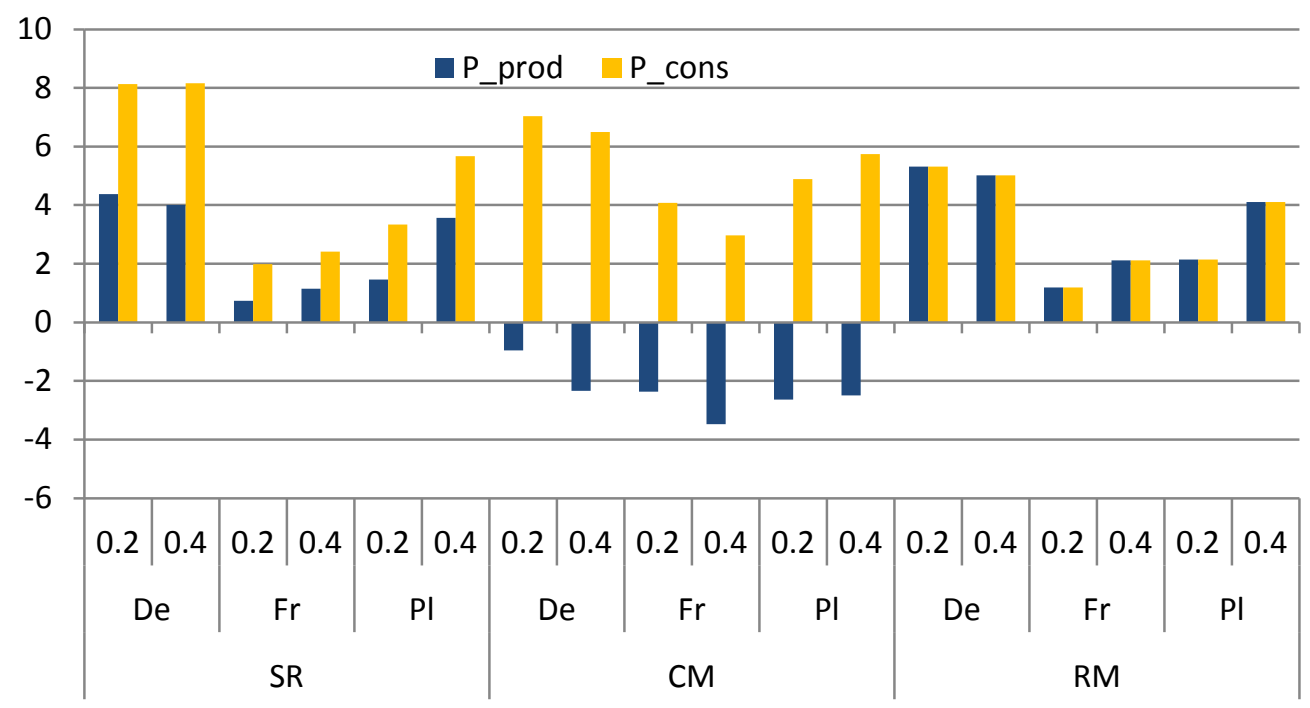

Figure 3: Policy effects on consumer and producer prices in Euro per MWh by 2033 for low (0.2) and high (0.4) elasticity.

while consumer price increases induced by CM-policy in Poland are reduced. Notably, by 2033 we find the strongest consumer price effects in Germany throughout policies and elasticities, which is explained by lower wholesale prices in Germany under EOM-regulation due to a particularly pronounced renewable energy roll-out. Consumer price impacts in Germany induced by the SR-policy reach up to 8.2 Euro per MWh, while the RM policy impacts increase to up to 5.3 Euro per MWh.

The changes of consumer and producer prices translate into shifts in consumer rents and profits. Additionally, the CM-Policy introduces a major revenue stream through the capacity market premium, which more than compensates generators for the reduction of wholesale prices. In Figures 4 and 5 below we show the combined effect on consumer and producer rents induced by the policies relative to our results for the EOM regulation, i.e. the welfare effects without accounting for the benefits of increased system security due to a five percent reliability margin. By 2023 a clear ranking of the welfare implications of policies emerges: Irrespective of the elasticity assumption, we find for all countries the RM-policy least welfare reducing, the SR-policy with intermediate impacts, and the CM-Policy least preferential. In percentage terms, France incurs the most pronounced impacts. Highest welfare losses are implied by a CM-policy in France with a reduction of more than 2 percent. By contrast, welfare reductions in France are limited to less than 1 percent due to the introduction of a RM-policy. Comparably low impacts on welfare are realized in Germany and Poland. In these countries the welfare losses attributed to a RMpolicy are below 0.2 percent and correspond to an almost complete transfer of rents from consumers to producers.

In the longer time perspective 2033, policies keep only in Germany the unambiguous ranking. To the contrary, in France and Poland the SR-policy turns out to be least preferential, and under a high elasticity the CM-policy appears to be superior compared to a RM-regulation as shown in Figure 5. 


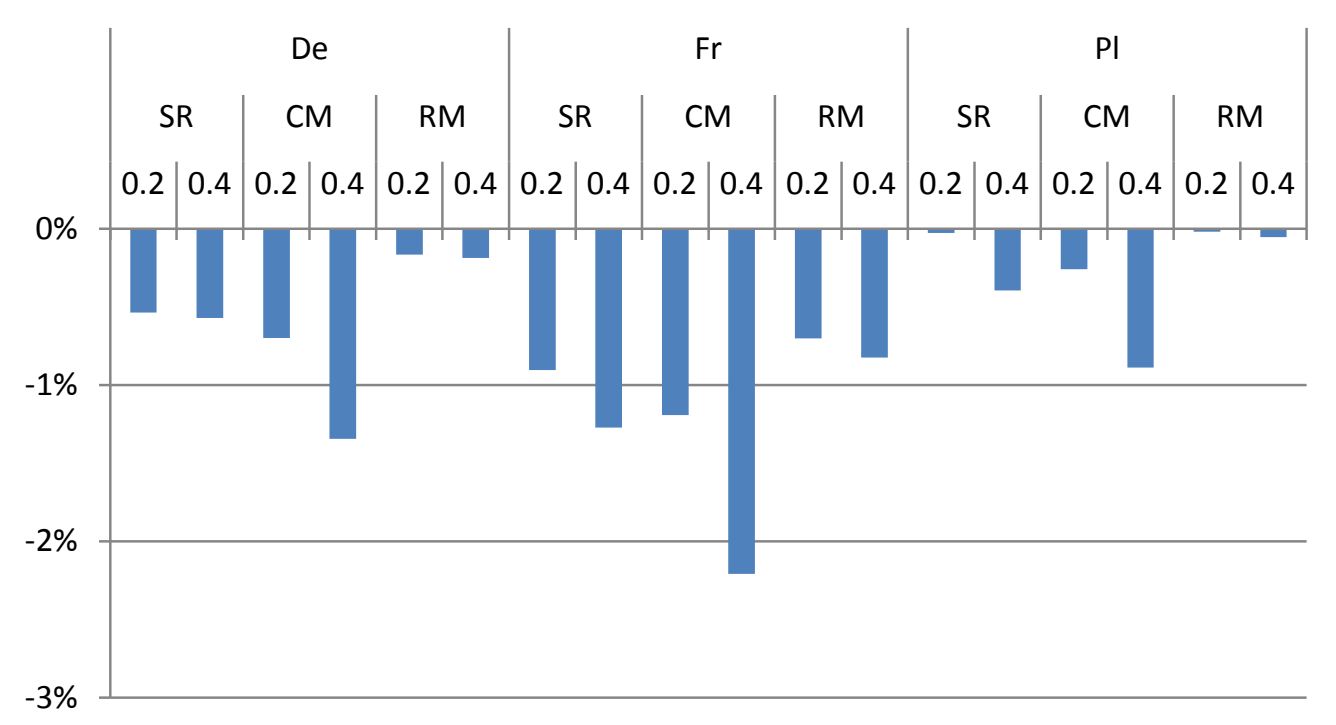

Figure 4: Welfare effects of capacity mechanisms relative to EOM by 2023 for low (0.2) and high (0.4) elasticity.

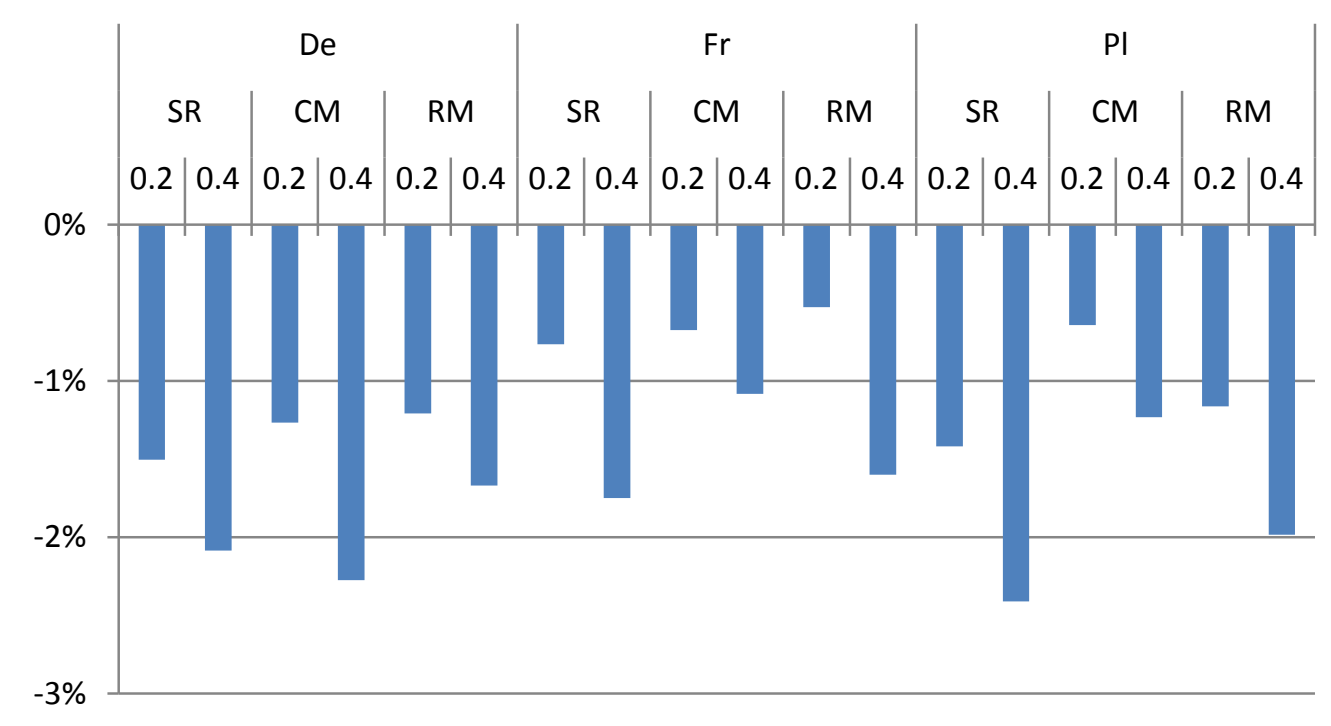

Figure 5: Welfare effects of capacity mechanisms relative to EOM by 2033 for low (0.2) and high (0.4) elasticity.

\subsection{Detailed impacts on the German market}

In this subsection we use the German example to highlight and explain important details of the effects of the different instruments.

As laid out in Figure 6 the three policies induce significantly different investments necessary to achieve the required firm capacity margin of five percent against peak load by 2023. Being the cheapest source of additional reliable capacity, retrofitting of old gas and oil fired capacities (Retrofit) is preferentially chosen to fill the capacity gap compared to the target, while new gas fired gas turbines (Gas GT) are used to supply capacity requirements in excess of the limit of retrofitting potential, i.e. 
4.8 GW by 2023 and 6.7 GW by 2033. Figure 6 shows furthermore that additional necessary capacity by the first model period varies in case of a high elasticity in total from 12.0 GW under a capacity market to no necessary additions in a system of RM policy. The strategic reserve policy requires intermediate capacity additions of at most $6 \mathrm{GW}$ by 2023. The outlook towards reference year 2033 shows that the capacity additions necessary in the CM-policy framework are highest, whereas they are lowest under RM-regulation. Furthermore, we find significantly increasing necessary capacity additions by period 2033 for all policies, indicating an potential adoption process of several decades: in period 2033 the instruments induce additional investments of between $11.8 \mathrm{GW}$ and $21.2 \mathrm{GW}$. These largely differing investment effects

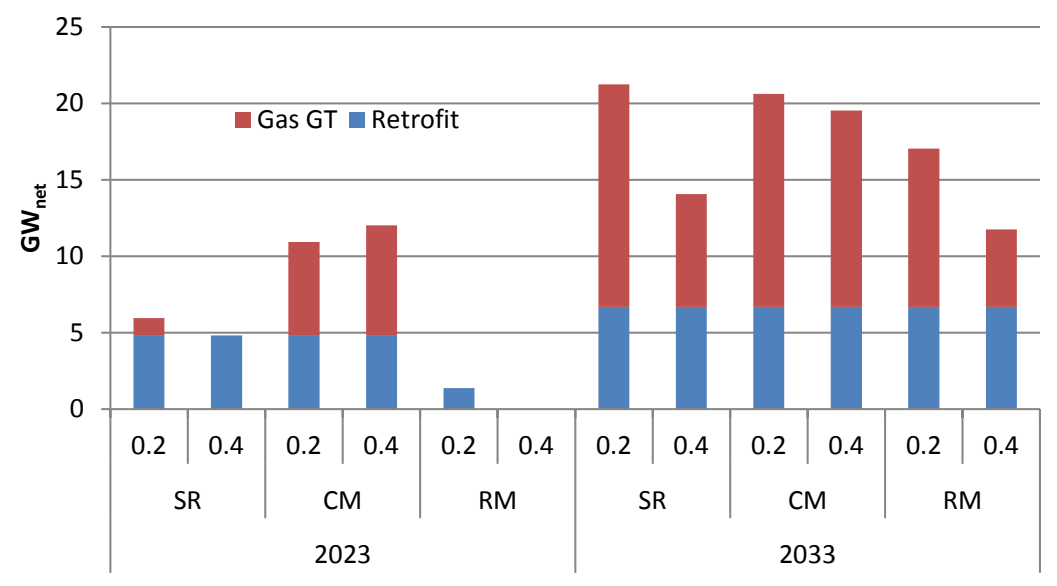

Figure 6: Investment effects in Germany in gigawatt net electric capacity of the policies Strategic Reserve (SR), Capacity Market (CM), and Reserve Market (RM) in conventional technologies for low (0.2) and high elasticity (0.4) by 2023 (left) and 2033 (right).

are explained by the impact of the policies on the utilization of plants, by the assignment of costs of the policies, and, ultimately, by the corresponding total effects on seasonal consumer prices and peak loads. In the following we shed some light on these aspects.

In case of a SR or RM policy, the induced firm capacity additions are not fully available for utilization in the energy market. The SR policy rather reduces significantly the capacities available for the generation market since 29 and $31 \mathrm{GW}$ of capacity are in equilibrium reserved by 2023 for the high and low elasticity scenarios respectively. By 2033 the strategically reserved capacities furthermore increase to more than $40 \mathrm{GW}$ in either scenario. The RM policy precludes electricity generation of capacity only under peak demand and amounts to between 3.3 and $3.6 \mathrm{GW}$ reserved for usage under peak demand conditions in both modeled periods.

The cost assignment is carried out through fees that are charged uniformly distributed over the modeled time steps within a period and within seasons, or prices of capacity certificates that reflect the scarcity of capacity in each time steps and each season. Figure 7 shows the fees charged to finance the SR and CM policies together with the price profiles of reserve capacity certificates (RPs) for the certificate market in winter and shoulder periods for the two elasticity scenarios and both 

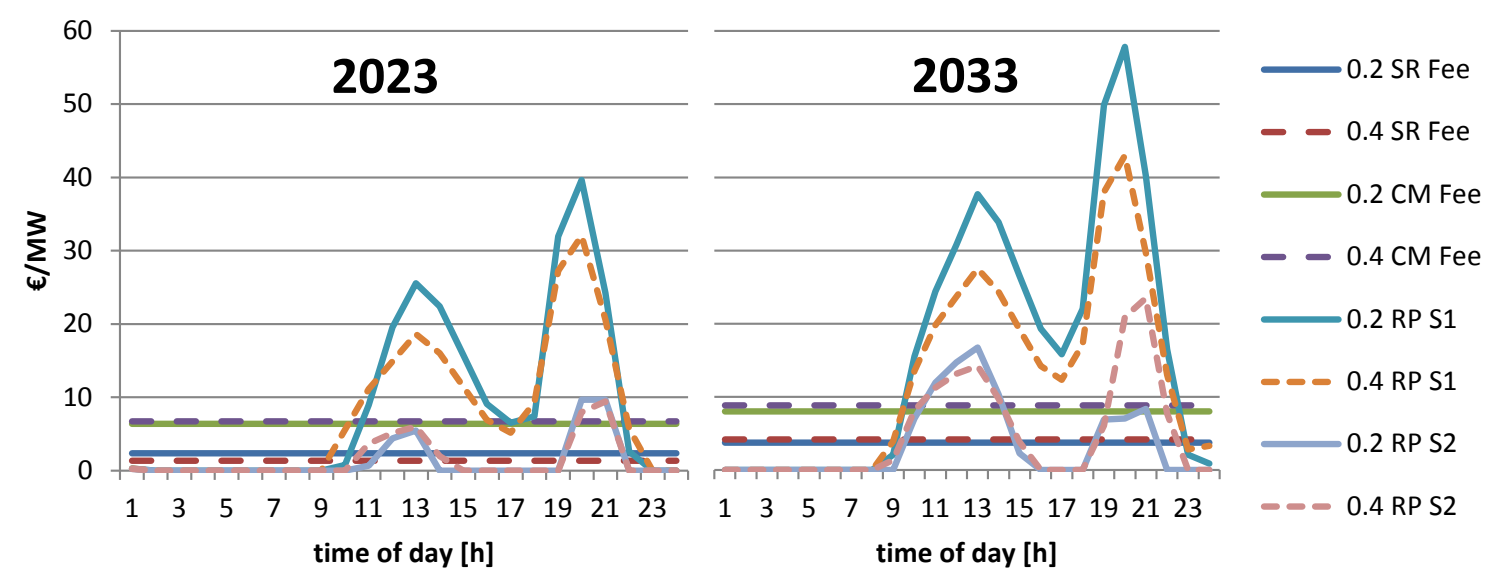

Figure 7: Fees for financing the costs of strategic reserve (SR Fee) and capacity markets (CM Fee), and prices for reserve market certificates in winter and shoulder periods (RP S1, RP S2) by 2023 (left) and 2033 (right) for high (0.4; dotted lines) and low elasticities $(0.2$; straight lines).

reference years. We find hourly reserve prices substantially varying over the days and over the seasons. They show pronounced spikes at noon and early evening in the winter season, while their levels are largely reduced in the shoulder season, and nearly vanish under summer and low wind winter conditions. This is explained by reduced demand for electricity on the one hand under the generally low consumption in summer, and, on the other hand, due to price spikes that reflect very low wind output in winter.

We also find that in the first reference period the reserve prices are lower under the assumption of a higher elasticity, since demand reactions are triggered more easily by electricity price changes. For the second reference period we find no influence of the elasticity on average certificate prices. An increased elasticity reduces winter prices and increases shoulder prices of certificates particularly in the early evening. This can be explained by dampened prices and an increase of demand in the historically lower load shoulder season, which progressively exhaust the capacity limit under the high elasticity assumption. Regarding averages, we find increasing certificate prices towards the second model period. The annual average of certificate prices grow from between 2.5 (high elasticity) and 2.7 Euro (low elasticity) per MW by 2023 to 5.7 Euro per MW in 2033 regardless of the elasticity assumption. This robustness against variations of the elasticity in the long term can be explained by a full decoupling from the energy market: the marginal unit necessary to provide sufficient capacities is not used for the energy market and its fixed costs has to be fully covered by certificate sales. Consequently, the average hourly certificate price in the second model period is independent from model variables as long as new reserve capacity has to be built.

Necessary uniform SR-fees are 2.4 and 1.3 Euro per MWh in the first period for the high and low elasticity assumptions respectively. The effect of elasticity can be explained by the change of the marginal technology: until 2023 and given a higher elasticity investments in comparatively cheap retrofitting are sufficient, whereas new 
OC units are necessary under a low elasticity scenario. By 2033 SR financing fees grow to around 4 Euro per MWh in either scenario. Comparing policies, we find SR fees significantly lower than the fees necessary to finance the CM-Policy. In the first model period they take values of about 6.6 Euro per MWh and increase up to around 8.4 Euro per MWh by 2033, with slightly lower values if the elasticity is low. The reason is that the capacity market depresses producer prices more pronounced under higher elasticity. Consequently, necessary capacity payments have to increase with elasticity to compensate for reduced energy market earnings.

Table 5 summarizes the effects on producer and consumer prices for electricity against the EOM results for both model periods and across seasons. In case of a strategic reserve the producer prices are on the one hand dampened by the demand reduction induced by the fees, and on the other hand increased by the reduction of capacities usable for generation. By 2023 we find in total an increase of producers prices compared to EOM of four Euro per MWh for the low elasticity scenario, and about two Euro per MWh for the high price elasticity scenario. In the long run 2033 the SR-policy induces a producer price increase of about four Euro per MWh under both elasticity assumptions. Moreover, we find high impacts on producer prices in the winter season, which are particularly pronounced under extreme low wind output and reflect the increased scarcity induced by the reserved capacities. This effect is partly due to our assumption that the reserved capacities are not used in the extreme situation, which is justified by simulated peak prices that by far do not reach contemporary proposals for threshold prices of several thousand Euro per MWh considered as trigger for the reserve activation. Price effects induced by the

\begin{tabular}{|c|c|c|c|c|c|c|c|c|}
\hline & \multicolumn{3}{|c|}{2023} & \multicolumn{4}{|c|}{2033} \\
\hline & & 0.2 & \multicolumn{2}{|c|}{0.4} & \multicolumn{2}{|c|}{0.2} & \multicolumn{2}{|c|}{0.4} \\
\hline & & \begin{tabular}{|l|l|} 
Prod & Cons \\
\end{tabular} & Prod & Cons & Prod & Cons & Prod & Cons \\
\hline \multirow{5}{*}{ SR } & Annual & $\begin{array}{ll}3.7 & 6.0\end{array}$ & 1.7 & 3.0 & 4.4 & 8.1 & 4.0 & 8.2 \\
\hline & Winter & $\begin{array}{ll}9.6 & 12.0\end{array}$ & 5.2 & 6.5 & 8.5 & 12.2 & 7.3 & 11.4 \\
\hline & Shoulder & 3.7 & 1.6 & 2.9 & 4.7 & 8.4 & 5.6 & 9.8 \\
\hline & Summer & 0.2 & -0.3 & 1.0 & 1.9 & 5.6 & 1.3 & 5.4 \\
\hline & Extreme & $\begin{array}{ll}34.6 & 37.0\end{array}$ & 13.6 & 14.9 & 23.4 & 27.2 & 18.0 & 22.2 \\
\hline \multirow{5}{*}{$\mathrm{CM}$} & Annual & -0.7 & -2.0 & 4.7 & -0.9 & 7.0 & -2.3 & 6.5 \\
\hline & Winter & -0.6 & -2.4 & 4.3 & $\begin{array}{l}-1.3 \\
\end{array}$ & 6.7 & -2.5 & 6.3 \\
\hline & Shoulder & -0.6 & -1.5 & 5.2 & -1.6 & 6.3 & -2.4 & 6.4 \\
\hline & Summer & -0.7 & -2.1 & 4.7 & -0.2 & 7.8 & -2.2 & 6.7 \\
\hline & Extreme & $\begin{array}{ll}-4.8 & 1.5\end{array}$ & -5.0 & 1.8 & -25.5 & -17.5 & \begin{tabular}{|l|}
-10.3 \\
\end{tabular} & -1.4 \\
\hline \multirow{5}{*}{ RM } & Annual & 2.7 & & .1 & 5 & 3 & 5. & .0 \\
\hline & Winter & 8.9 & 6 & .1 & 16 & 5.0 & 12 & 2.1 \\
\hline & Shoulder & 1.3 & 1 & .4 & 2 & 6 & 3. & .9 \\
\hline & Summer & 0.0 & 0 & .2 & 1 & .1 & 1. & .8 \\
\hline & Extreme & -1.7 & & .6 & -1 & 7.3 & -5 & .1 \\
\hline
\end{tabular}

Table 5: Average and seasonal price effects of policies on producer and consumers compared to EOM prices by 2023 and 2033 in Germany in Euro per MWh for low (0.2) and high (0.4) elasticity.

SR policy on consumers are the sum of producer price effects and necessary financing 
fees. Table 5 shows in annual assessment a dominance of producer price effects in the first reference year 2023, whereas by 2033 average consumer prices are equally impacted by both components. However, in a seasonal perspective the simulated consumer price effects are largely dominated by the referenced producer price effects in winter and shoulder seasons. Thus, incentives of the SR policy in regard to peak demand reduction mainly stem from the exclusion of reserved capacities from the power market, while the fees tend to reduce summer demand without effect on annual peak load.

The introduction of a capacity market scheme with uniform financing fees reduces the simulated average electricity producer prices as shown in Table 5 by between about one and two Euro per MWh compared to the EOM, with minor seasonal differences compared to the other policy options. Only in the extreme low wind situation in winter the price dampening effects are significantly more pronounced. Particularly, in the long term electricity wholesale prices under such extreme conditions are largely depressed by between 25.5 and 10.3 Euro per MWh compared to EOM results. This reflects the prevention of scarcity pricing with price rationing of consumers under a CM policy.

However, the producer price reductions are more than compensated by the necessary capacity market fees across seasons and result in total in pronounced consumer price increases. We find consumer price increases of between about five and six Euro per MWh in the first and up to 7 Euro per MWh in the second model period. Moreover, the impacts on consumer prices are almost uniformly distributed across seasons, since the financing fees are dominant. However, the CM policy may induce a consumer price reduction under low wind conditions in winter as suggested by our results for reference year 2033.

Contrasting the other two policies, the RM approach induces electricity price changes equally to consumers and producers. In comparison with the other policies, we find moderate and more robust impacts in regard to elasticity assumptions. Price increasing effects amount to about five percent in the first period and up to ten percent in the second period, i.e. of around 2.5 to 5 Euro per MWh. Most pronounced price increases are triggered by the RM policy in the peak load winter season under normal wind conditions, while prices under extremely low wind conditions in winter are dampened. Under these conditions prices are leading to reduced demand compared to normal wind output and consequently the capacity scarcity is reduced. Contrasting the effects of a SR policy, new built capacity induced by the RM policy is partially free to dampen price peaks. In summary, our modeling shows that price impacts on consumers compared to EOM prices may be limited to below 9 percent by the implementation of efficient pricing. The investigated capacity mechanisms that does not allocate costs by cause leads to more pronounced effects on consumer prices of up to around 12 percent. Implementation of a long-term SR-policy may, however, lead to the highest consumer price increases of up to 14 percent.

The referenced consumer price increases in the winter season are particularly influential for the developments of total annual peak loads. Peak loads in 2023 are simulated to range between $74.0 \mathrm{GW}$ to $74.5 \mathrm{GW}$ under a SR-regulation, whereas 
a capacity market supports peak loads of between 79.1 and 80.1 GW. By contrast, the RM-regulation is calculated to induce peak loads of only 69.6 to $70.8 \mathrm{GW}$ on the same time scale. Moreover, differences in supported peak loads are increasing towards the second reference period, and the elasticity assumption plays an even more important role. Assuming a low elasticity leads in 2033 to peak loads of 79.0 GW under SR policy and 71.4 GW under the RM policy setting. By contrast, under high elasticity scenario the corresponding peak loads are only 71.7 and $65.6 \mathrm{GW}$ under SR and RM policies respectively. Introducing the CM policy leads by 2033 to simulated peak loads of $82.9 \mathrm{GW}$ under both elasticity assumptions. Including a five percent reserve margin, simulated firm capacity requirements vary between 73.1 GW and 84.1 GW by 2023, and between 68.8 GW and $87.1 \mathrm{GW}$ by 2033 .

Corresponding with the distinct effects on producer prices are the additional rents induced for existing capacities by the analyzed policies under different elasticities. Figure 8 summarizes the impacts on operating profits for existing lignite $(\mathrm{BC})$, hard coal (HC), gas combined cycle (CC), and natural gas fired gas turbine (GT) power plants.

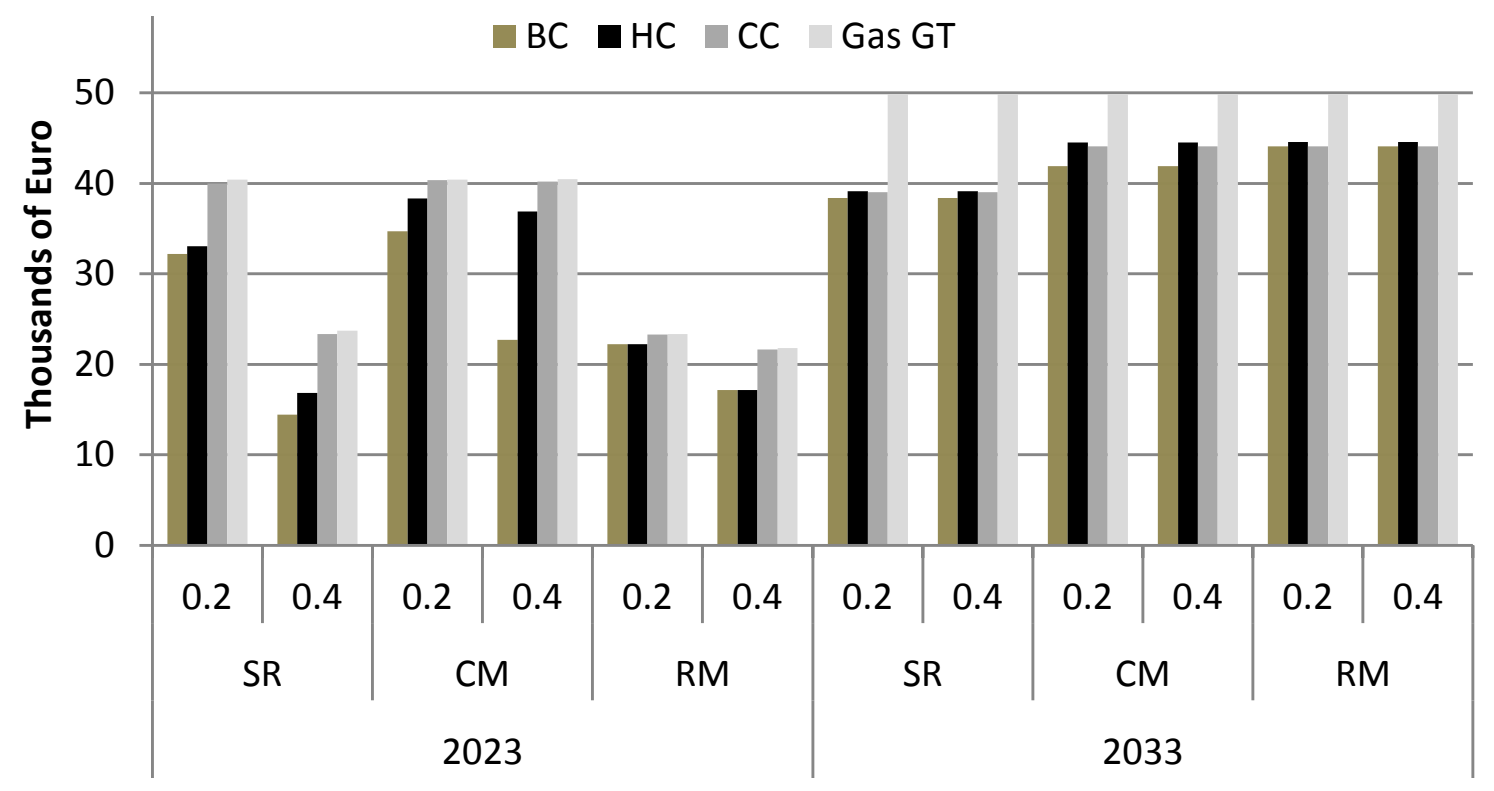

Figure 8: Effect of policies on annual operating profits per available MW of existing fossil fired capacities by 2023 and 2033 for low (0.2) and high (0.4) elasticity.

By reference year 2023, additional profits accruing for fossil fueled units by the SR policy vary between annually around 14 thousand Euro per available MW for lignite power plants under higher elasticity to 40 thousand Euro for gas fired power plants under low elasticity. Under a high elasticity assumption the retrofit of existing capacities is sufficient, whereas the assumption of a low elasticity necessitates new capacities. In consequence, SR-payments increase due to higher costs of new units. Technological distinct effects depend on the participation in the reserve: Reserved capacities receive their reserve payment and forgo their rents on the energy market, while not reserved capacities benefit from higher prices due to reduced energy market capacity. Since forgone energy rents are minimal in case of natural gas fired GTs, the 
reserve payment is almost completely reflected in the effects on operating profits of these units in Figure 8. However, in both scenarios the other technologies experience lower effects on profits: Either they sacrifice a higher EOM energy rent for the participation in the reserve, or they benefit less pronounced by the price increases. Moreover, technologies that can increase their output compared to the utilization under EOM, e.g. hard coal units, benefit potentially more pronounced compared with technologies that are fully utilized in all scenarios.

Similarly, by reference year 2023 implementation of a CM increases operating profits of gas fired gas turbines due to only minor forgone energy rents most significantly. These capacities gain almost the full capacity payment. Lower electricity prices and consequent reductions of energy rents compared to the EOM clearly impact the more utilized coal fired technologies to a larger extent. In case of a high elasticity scenario the CM reduces the energy rents of lignite power plants by the first model period by more than forty percent of the capacity payments as indicated by Figure 8 . By contrast, the introduction of a reserve capacity trading system effects technologies in reference year 2023 rather neutrally and more robust with regard to the elasticity of demand. However, we find a minor distinction between coal and gas fired technologies, which is explained by the necessary payments for capacity certificates, which partially compensates additional energy rents.

By 2033, the increase in operating profits of gas turbines does not vary across instruments. Their profits are highlighted on the right hand side of Figure 8 and reflect the annuities of new built capacities over the remaining time horizon. Moreover, in the long term the differences in policy impacts on the remaining technologies are less pronounced compared to the first reference period. Furthermore, the sensitivity of profit effects in regard to elasticity assumptions almost vanish. We thus find differences in the impacts of different instruments on conventional power plant revenues to be more important in the medium term perspective.

Regarding the total generation sector, the implementation of SR-Policy increases profits in Germany most pronounced by up to 3.13 billion Euro in 2023 and up to 3.5 billion Euro in 2033. The CM-policy is calculated to lead to intermediate gains of generators of up to 2.5 billion Euro by 2023 and up to 2.8 billion Euro in 2033. The most cost effective policy of the RM-regulation limits additional profits for generators to about 1.5 billion Euro by 2023 and to at most 2.5 billion Euro by 2033.

\section{Conclusion}

We develop a multi-period market and investment model of the central European regions Germany, France and Poland to analyze effects of the introduction of different capacity mechanisms. A strategic reserve policy, a simple capacity market and a certificate market for reserve capacities are investigated. Effects of policies that are largely depending on the elasticity of demand, the existing generation structure of the analyzed markets, and the time perspective evolve. 
We show for the German case how existing capacities and assumed elasticities influence the medium term effects on investments, prices and the profitability of technologies. Under high elasticity and a strategic reserve policy or a reserve capacity certificate market, the potential for the retrofit of old gas fired and oil fired units are more than sufficient to fulfill the demand for new capacities until 2023. By contrast, in the first model period a simple capacity market completely exhausts the relatively cheap potential of retrofitting irrespective of the elasticity scenario. Consequently, the premium for capacities has to compensate the comparatively high costs of new built power plants. By 2033, retrofit of capacities is becoming insufficient under all policies, and the costs of new built gas fired gas turbines determine capacity payments. The necessary payments lead to consumer price increases between 5 and 8.2 Euro per MWh in Germany, i.e. between 9 and 14 percent of electricity wholesale prices under EOM-regulation in 2033.

The three investigated policies are ranked according to the welfare reductions necessary to achieve a five percent reserve target. Our analysis suggests for the German case that a RM-policy is superior to the SR-policy, which in turn is preferable to the introduction of a CM-policy. These results are explained by dampened peak loads due to the price signals of a RM-policy, a major share of unused capacities under a strategic reserve policy, and insufficient scarcity pricing in a simple capacity market system. In the long term, the RM-policy creates about 2.5 billion Euro additional rents for generators, whereas the SR-policy induces rents of more than 3.5 billion Euro. Moreover, the CM-policy induces intermediate additions of rents that are with up to 2.8 billion Euro comparable in the long term to the effects of the RM policy. However, the CM-Policy policy creates unnecessarily high rents already in the first model period. Hence, our analysis clearly shows advantages of the RM-policy setting. There are, however, some limitations to the analysis conducted in the present work.

Firstly, we model an ideal capacity certificate market without frictions. This concerns information requirements and the potential abuse of market power. To coordinate the efficient allocation of reserve capacity among hundreds of potential suppliers, intermediaries and demand on hourly basis may involve significant transaction costs which are not modeled, and may add to certificate prices. Furthermore, the certificate market may be dominated by a small number of suppliers that control relevant power plants, e.g. gas or coal fired power plants. An advanced policy recommendation would have to take potential market power aspects into account. Moreover, monitoring of the fulfillment of capacity requirements could induce significant costs for the regulator and poses the problem of determining a penalty for deviations from the requirements.

Secondly, the model simulation is based on perfect foresight. This reduces necessary payments for investment under political or market induced uncertainty and risk averse investors. In addition, it neglects the costs due to unpredicted demand developments with necessary readjustment of capacity targets under the SR- and CM- policy in order to keep a fixed target for the reserve margin. The related risk could lead investors to demand further risk premia under the regulations with absolute capacity targets. Furthermore, the model does not attempt to quantify the 
value of reliability and the costs of supply interruptions, and is therefore not able to carry out a full welfare analysis.

Thirdly, our reference energy market regulation of EOM does not provide incentives to supply firm capacity, although most energy markets have further regulations for the reliability of the electricity system. For instance, in Germany suppliers are obliged to balance electricity provision and sales ex post. If demand cannot be covered by procured generation, companies have to pay for necessary balancing capacities. This provision leads to income for balancing capacities either on the balancing market or within the companies to prevent balancing energy payments, and provides some level of firm capacity in the current regulatory framework. A strengthening of these requirements to induce longer term reliability could furthermore substitute a policy with administratively predefined capacity targets.

The research conducted for this paper provides a basic tool for the analysis of further aspects concerning policies for capacity reliability. Important issues for the future research agenda include the analysis of potential market power aspects in reliability certificate markets, the detailed impacts of policies on specific renewable energy market values, and, an asymmetric introduction of policy across European countries and their trade effects.

\section{References}

ARE (2011). Aktualizacja prognozy zapotrzebowania na paliwa i energie do roku 2030. http://www.mg.gov.pl.

Beurskens, L. and M. Hekkenberg (2011). Renewable energy projections as published in the national renewable energy action plans of the european member states. ECN. https://www.ecn.nl.

Boiteux, M. (1960). Peak-load pricing. The Journal of Business 33(2), 157-179.

Chao, H.-p. (1983). Peak load pricing and capacity planning with demand and supply uncertainty. The Bell Journal of Economics 14, 179-190.

Crew, M. A. and P. R. Kleindorfer (1976). Peak load pricing with a diverse technology. The Bell Journal of Economics 7, 207-231.

de Vries, L. and R. Hakvoort (2004). The question of generation adequacy in liberalised electricity markets. INDES Working Papers.

de Vries, L. and P. Heijnen (2008). The impact of electricity market design upon investment under uncertainty: The effectiveness of capacity mechanisms. Utilities Policy 16(3), 215-227.

ENTSOE (2011a). Indicative values for net transfer capacities (ntc) in continental europe - summer 2010.

ENTSOE (2011b). Indicative values for net transfer capacities (ntc) in continental europe - winter 2010-2011. 
Hobbs, B., J. Iñón, and M. Kahal (2002). A review of issues concerning electric power capacity markets. Project report submitted to the Maryland Power Plant Research Program, Maryland Department of Natural Resources.

Joskow, P. (2006). Competitive electricity markets and investment in new generating capacity. AEI-Brookings Joint Center Working Paper.

Joskow, P. and J. Tirole (2007). Reliability and competitive electricity markets. The Rand Journal of Economics 38(1), 60-84.

Joskow, P. L. (2008). Capacity payments in imperfect electricity markets: Need and design. Utilities Policy 16(3), 159-170.

Oren, S. (2003). Ensuring generation adequacy in competitive electricity markets. University of California Energy Institute's (UCEI) Energy Policy and Economics Working Paper Series.

RTE (2013). Generation adequacy report on the electricity supply and demand balance in France 2012. Réseau de transport d'électricité. http://www.rtefrance.com.

Schröder, A., F. Kunz, J. Meiss, R. Mendelevitch, and C. v. Hirschhausen (2013). Current and prospective costs of electricity generation until 2050. DIW Berlin Data Documentation. http://www.diw.de/.

ÜNB (2013a). Bericht der deutschen Übertragungsnetzbetreiber zur Leistungsbilanz 2013. Amprion-50Hertz-TenneT-TransnetBW. http://www.bmwi.de/DE/Mediathek/publikationen,did=600668.html.

ÜNB (2013b). Netzentwicklungsplan. Amprion-50Hertz-TenneT-TransnetBW. http://www.netzentwicklungsplan.de.

Vásquez, C., M. Rivier, and I. J. Pérez-Arriaga (2002). A market approach to longterm security of supply. IEEE Transactions on Power Systems, 17(2), 349-357.

VGB (2012). Verfügbarkeit von Wärmekraftwerken 2002 - 2011. 


\section{Abbreviations}

EOM Energy only market regulation; indicating the baseline without capacity policy

$\mathrm{CM}$ Capacity market; indicating administratively implemented capacity market

$\mathrm{RM}$ Reserve Obligation with Capacity Certificate Market

SR Srategic reserve; indicating administratively implemented reserve capacity policy

$0.2 \quad$ Indicating scenario with low elasticity (-0.2)

$0.4 \quad$ Indicating scenario with low elasticity (-0.4)

BC Brown coal power plant

CC Combined cycle gas power plant

GT Gas turbine power plant, e.g. Gas GT

HC Hard coal power plant

ST Steam turbine power plant, e.g. Gas ST

S1 Winter season

S2 Shoulder season

S3 Summer season

S4 Low wind event in winter season, i.e. extreme situation 